\title{
Effect of different parameters on the tensile properties of printed Polylactic acid samples by FDM: Experimental design tested with MDs simulation
}

\author{
Ashkan Farazin \\ University of Kashan \\ Mehdi Mohammadimehr ( $\square$ mmohammadimehr@kashanu.ac.ir ) \\ University of Kashan
}

\section{Research Article}

Keywords: Tensile properties, Fused Depositional Modeling, Mechanical properties, Molecular dynamics simulation, Failure strain

Posted Date: March 19th, 2021

DOl: https://doi.org/10.21203/rs.3.rs-273321/v1

License: (c) (1) This work is licensed under a Creative Commons Attribution 4.0 International License. Read Full License

Version of Record: A version of this preprint was published at The International Journal of Advanced Manufacturing Technology on May 31st, 2021. See the published version at https://doi.org/10.1007/s00170-021-07330-w. 


\section{Abstract}

Fused Depositional Modeling (FDM) is one of the common methods for 3D printing of polymers, which is expanding in various industrial applications, scientific researches, and engineering applications due to its ability to make complex parts. In this research, molecular dynamics (MDs) simulation has been used to predict the physical and mechanical properties. Then, the mechanical properties of the printed parts are obtained. The mechanical properties of 3D printed parts strongly depend on the correct selection of processing parameters. In this study, the effect of three important parameters such as infill density, printing speed, and layer thickness are investigated on the tensile properties of PLA specimens. For this purpose, standard specimens with four infill densities of $20 \%, 40 \%, 60 \%$ and $80 \%$, two speeds of 20 $\mathrm{mm} / \mathrm{s}$, and $40 \mathrm{~mm} / \mathrm{s}$, and two thicknesses of $0.1 \mathrm{~mm}$ and $0.2 \mathrm{~mm}$ are printed and tested under quasistatic tensile test. In all printed specimens, the print angle is $\pm 45^{\circ}$. The experimental results show that the infill density in comparison to the other two parameters has significant effect on mechanical properties such as modulus of elasticity, ultimate strength, and failure strain. According to these results, by increasing the infill density, the stiffness and strength of the specimens increases considerably. At infill density of $80 \%$, the specimens has the highest stiffness and strength, but it exhibits a brittle behavior. Moreover, it can be deduced that by reducing the layer thickness although the modulus of elasticity increases a little, ductility is greatly affected.

\section{Introduction}

Three dimensional (3D) printing is one of the fast prototyping methods that produces the product using a $3 \mathrm{D}$ model created by a computer [1-5]. 3D printers are used in various industries such as mechanical, automotive, aerospace, civil, and medical engineering. For example, a 3D printer can be used to produce prototypes, molds, screws or gears used in robots, plastic parts for some machines, veneers for some prostheses, fiber composites, and more [6,7]. The production process of 3D printing is based on the additive manufacturing process [8]. In the additive manufacturing process, the layers are stacked one after the other, eventually turning a computer-generated 3D file into a physical product. Today, the use of additive manufacturing technology has increased due to its flexibility, and design advantages [9-13]. For example, this technology allows the creation of complex shapes and structures with less weight, reduces development time and tool costs, and dramatically simplifies the production process [14-18]. Also, using this method, parts that are made of several assembly parts are made as a single object without assembly. Also, by using this method, parts that are made of several assembly parts are made as a single object without assembly [19-23]. 3D printers are capable of printing a variety of materials such as metals, ceramics and polymers. Types of 3D printers for polymer printers include: Fused deposition modeling (FDM), Stereo lithography (SLA), Digital light processing (DLP), Selective laser sintering (SLS), and laminated objective manufacturing (LOM), Liquid Deposition Modeling (LDM) (ceramic 3D printer) $[24,25]$. 3D printers of FDM are one of the most common 3D printing methods in which extruded filaments of thermoplastic polymers are used to produce the part [26-30]. The extruder is placed on a three-dimensional CNC table that moves in the $x, y$ and $z$ directions and places the molten polymer inside 
the extruder on the part [31,32]. After finishing one layer, the extruder moves upwards as thick as one layer [33-37]. It is important to note that many parameters affect the quality and final properties of a sample printed with FDM [38-42]. Construction parameters can be divided into three general categories: 1) Slicing parameters. The most important of these parameters are: Thickness of layers, Number and walled thickness, Print speed, Nozzle diameter, Printing angle, Feed rate, Infill density, and Infill (raster) pattern. 2) Building orientation: Samples can be printed and made horizontally, vertically or transversely. 3) Temperature conditions: includes ambient temperature, nozzle temperature and desktop temperature [43-45]. Recently, many studies have been performed on the mechanical properties of 3D polymer samples printed by FDM method, and these studies show the importance of paying attention to 3D printing parameters. Most recent research has focused on the effect of second-and third-group fabrication parameters on the behavior of samples printed with Acrylonitrile Butadiene Styrene (ABS) filament, while Polyactic Acid (PLA) filament, despite its unique properties, has received less attention from researchers [46-50]. For example, a group of researchers studied the effect of print parameters such as layer thickness, direction and printing angle on mechanical properties using ABS and PLA filaments. Croccolo et al. [51] studied the direction and angle of printing of ABS specimens. Tymrak et al. [52] investigated the effect of printing angle parameters and the thickness of the sample layers with PLA. Chacon et al. [53] studied the printing direction, layer thickness and filament exit rate and performing three-point tensile and flexural tests, they found that the PLA samples which printed by the FDM printer in the horizontal direction has the best mechanical properties by decreasing the layer thickness and increasing the filament exit rate. Kozior et al. [54] investigated the mechanical properties of PLA samples produced by FDM printers in various printing directions by pressure testing. Mahmood et al. [55] studied the tensile properties of ABS specimens by examining the parameters of layer width and thickness, sample filling density, number of walls and printing direction. Alafaghani et al. [56] investigated the effect of the mechanical properties and increasing the accuracy of PLA samples printed by FDM printer by researching the parameters of layer thickness, printing speed, nozzle temperature, sample internal network filling density, internal network filling pattern, and printing direction. Tronvoll et al. [57] tried to increase the dimensional accuracy, and smoothness of the surface of printed specimens with helical, and sloping surfaces (such as screws) by changing the layer height parameter and using a linear pattern. Popescu et al. [58] reviewed existing articles on the effect of FDM printer parameters on the mechanical properties of polymer samples. Khandan et al. [59] printed a mitral heart valve with Polyurethane polymer by FDM method and checked its properties by MDs simulation. They also examined tensile strength, strain at fracture, permeability, and the ultimate tensile strength to monitor the mechanical property of this artificial heart valves.

A review of the above sources shows that most recent research has focused on the effect of print angle and direction and filling density on mechanical properties. While the printing speed and layer thickness can have a great impact and also for predicting the mechanical and physical properties by MDs simulation that is another novelty of this article. On the other hand, in these studies in the literature review, only the modulus of elasticity and strength (among the mechanical properties) is considered and the effect of changing the parameters on fracture strain, weight of the produced part, printing time, and 
consequently costs are not discussed. Also, among the researches, only two researchers have studied the effect of printing speed on mechanical properties, which in both studies, high speeds have been considered. Since the three parameters of filling the internal network of the sample, printing speed and layer thickness have a significant effect on the fabrication time of the part and so far these three parameters have not been studied together, in this study, the effect of these three fabrication parameters on the properties of PLA polymer specimens including stiffness, ultimate strength and final strain of fracture are investigated and finally the most suitable conditions in terms of weight and printing time are introduced and simulated.

\section{Materials And Method}

\subsection{Introduction of PLA and its molecular structure}

PLA is a linear aliphatic thermoplastic polyester that can be completely extracted from renewable sources such as corn [60]. Of course, its use has been limited to medicine such as sutures. But today this polymer is widely used in many industries [61]. PLA is very similar to plastic [62]. This thermoplastic film is biodegradable and a combination derived from the renewable plant sources of corn and sugar beet [63]. PLA is one of the few polymers whose molecular structure can be controlled by the ratio of isomers $L$ and D to obtain a crystalline or amorphous polymer with high weight as shown in Fig. 1 [64].

PLA is known as a food safety agent and can come into contact with food. This polymer decomposes without the need for a catalyst by hydrolyzing ester bonds. The rate of decomposition depends on the shape and size of the polymer object, the isomer ratio and the hydrolysis temperature as shown in Fig. 2. In general, the physical and chemical properties of lactic acid are given in Table 1 [65-67].

Table 1

Physical and chemical properties of lactic acid

\begin{tabular}{|ll|}
\hline Properties & value \\
\hline Chemical formula of PLA & $\left(\mathrm{C}_{3} \mathrm{H}_{4} \mathrm{O}_{2}\right)_{\mathrm{n}}$ \\
\hline Molecular weight $(\mathrm{g} / \mathrm{mol})$ & 90.08 \\
\hline Solubility & Completely soluble in water \\
\hline Density $\left(\mathrm{g} / \mathrm{cm}^{3}\right)$ & 1.2 \\
\hline Percentage of volumetric volatility $\left(\mathrm{at} 21^{\circ} \mathrm{C}\right)$ & 0 \\
\hline Boiling point $\left({ }^{\circ} \mathrm{C}\right)$ & 122 \\
\hline Flash point $\left({ }^{\circ} \mathrm{C}\right)$ & 112 \\
\hline Viscosity at temperature $25^{\circ} \mathrm{C}(\mathrm{CP})$ & 36.9 \\
\hline Vapor pressure at $25 \mathrm{mmHg}$ & 0.0813 \\
\hline
\end{tabular}


In this paper, as shown in Fig. 3, the simulation of PLA was performed by MDs method. The element of PLA as shown in Fig. 4 is simulated by Materials studio software to predict the mechanical and physical properties before fabrication.

\subsection{Simulation Steps, Force field, and software}

In this article, the MDs method is applied to predict and obtain the significant mechanical and physical properties of simulated PLA [68-70]. The following steps have been taken to complete the molecular dynamics method as shown in Fig. 5.

The initial atomistic models are created in Materials Studio software and Condensed-phase Optimized Molecular Potentials for Atomistic Simulation Studies (COMPASS27) force field is determined for modeling inter- and intra-atomic interactions. The COMPASS parameters for covalent molecules are completely confirmed using various calculation techniques including extended molecular dynamics simulations of liquids, crystals, and polymers. COMPASS is the first ab-initio force field able to foretelling thermo-mechanical properties of polymers like polymer nanocomposites perfectly. NVE explains that the sum of kinetic (KE) and potential energies (PE) is conserved, $T$ and $P$ are unregulated and $N, V$, and $E$ denote a constant number, volume, and energy, respectively. At this step, the simulation box is placed at a temperature of $298^{\circ} \mathrm{K}$ under NVE. The simulation time is considered $100 \mathrm{ps}$.

NVT represents that temperature $(T)$ is regulated via a thermostat, which typically adds a degree of freedom to the conserved Hamiltonian; KE and PE are included in the Hamiltonian; $\mathrm{P}$ is unregulated. At this part, the simulation box is set at the temperature of $298^{\circ} \mathrm{K}$ under NVT. The initial density of the system $\left(0.9 \mathrm{gr} / \mathrm{cm}^{3}\right)$ is assumed to allow molecules and atoms to be displaced to move towards optimal mode. The simulation time considered 100 ps.

NPT is similar to NVT, but the pressure $(P)$ is regulated. Density is one of the physical properties that is considered in atomic modeling. It determines the accuracy of the density of the atoms in equilibrium. If the atomic modeling path is followed correctly, the density of the atomic system is expected to be close to the actual density of the system in comparison to the macro. Furthermore, it is assumed that after the simulation time, the amount of any quantity attributed to the system of atoms, including the converged density of the solution fluctuations, will decrease over time. At this point, the system is pressurized at atmospheric pressure 1 at a temperature of $298^{\circ} \mathrm{K}$ under a constant NPT to close the system density to the actual density. NPT can also eliminate system tensions. The simulation time at this stage considered 100 ps.

\subsection{Experimental work}

PLA filament is one of the most widely used filaments in 3D FDM printers. This filament has unique properties compared to other filaments. These properties include: 1) PLA is a thermoplastic polymer that is generally produced from lactic acid from corn and sugar beet therefore, it is recyclable. 2) In addition to being recyclable, low environmental impact and it is highly compatible with the human body. 3) An 
important advantage of this filament is that it does not emit gas during printing. Therefore, it allows printing to be done at home, in classrooms, and factories without special ventilation. 4) These filaments do not need a warm bed. Therefore, there will be no problems in the cooling process such as partial shrinkage and cracking. 5) The melting point of PLA filament is between $180-230^{\circ} \mathrm{C}$. Given these advantages, this study focuses on the mechanical behavior of PLA filaments. It should be noted the diameter of the filament that used in this research is $1.75 \mathrm{~mm}$.

\subsection{Sample preparation}

First, the standard sample of tensile test as shown in Fig. 6 is modeled according to Type I standard ASTM D638 in Solid works software and then save as extension of *.STL [71].

Then the modeled *.STL file is converted to G-Code using Cura software. It should be noted that in most cases, during the process of converting the model to STL and then G-code, the geometry of the part loses its dimensional accuracy slightly. Cura software is one of the most comprehensive and practical 3D printing software. This software uses a very advanced graphical environment that is equipped with a layering simulator. Using this simulator, all different manufacturing parameters can be applied to create *.STL model. Therefore, in the next step, different parameters of model making are selected in this software. Table 2 shows the technical specifications of the 3D printer used to print SP1-SP6 samples. Figure 7 shows the overview of 3D printer that printed specimens (SP1-SP6) in the present work.

Table 2. Technical specifications of the 3D printer used to print SP1-SP6 samples

\begin{tabular}{cc}
\hline Manufacturing technology & FDM \\
\hline Print dimensions $(\mathrm{cm})$ & $30 \times 30 \times 30$ \\
\hline Print layer thickness $(\mu \mathrm{m})$ & At least 20 \\
\hline Default Printing Speed $(\mathrm{mm} / \mathrm{s})$ & 60.00 \\
\hline Solid Infill Underspeed $(\%)$ & 60.00 \\
\hline Outline Underspeed $(\%)$ & 60.00 \\
\hline Support Structure Underspeed $(\%)$ & 65 \\
\hline X/Y Axis Movement Speed $(\mathrm{mm} / \mathrm{s})$ & 112 \\
\hline Z Axis Movement Speed $(\mathrm{mm} / \mathrm{s})$ & 16.7 \\
\hline Nozzle diameter $(\mathrm{mm})$ & 0.4 \\
\hline Consumption filament diameter $(\mathrm{mm})$ & 1.75 \\
\hline Extruder temperature $\left({ }^{\circ} \mathrm{C}\right)$ & $\mathrm{Up}$ to 270 \\
\hline Construction plate temperature $\left({ }^{\circ} \mathrm{C}\right)$ & $\mathrm{Up}$ to 80 \\
\hline
\end{tabular}

In order to investigate the effect of the internal network density parameters of the sample, the printing speed, and the thickness of the sample layer were made according to the specifications given in Table 3 and during the time that presented in this table. 
Table 3

Different processing parameters with their processing time

\begin{tabular}{|lllll|}
\hline $\begin{array}{l}\text { Sample } \\
\text { code }\end{array}$ & $\begin{array}{l}\text { Infilling density } \\
(\%)\end{array}$ & $\begin{array}{l}\text { Print speed } \\
(\mathbf{m m} / \mathbf{s})\end{array}$ & $\begin{array}{l}\text { Thickness of layers } \\
(\mathbf{m m})\end{array}$ & $\begin{array}{l}\text { Print time } \\
(\mathbf{m i n})\end{array}$ \\
\hline SP1 & 20 & 40 & 0.2 & 35 \\
SP2 & 40 & 40 & 0.2 & 41 \\
SP3 & 60 & 40 & 0.2 & 47 \\
SP4 & 80 & 40 & 0.2 & 53 \\
SP5 & 40 & 20 & 0.2 & 81 \\
SP6 & 60 & 40 & 0.1 & 92 \\
\hline
\end{tabular}

According to the standard, at least five samples must be made and tested for each case to prove the reproducibility of the results. Due to changes in manufacturing conditions and adverse events that may occur during the manufacturing process, and the scattering of data in printed samples may be high in some cases. Therefore, in this study, the results of the three samples that had the highest repeatability were reported. It should be noted that the rest of the construction parameters such as the thickness of the initial layer, the width of each layer, walled thickness are fixed in all samples and their values are listed in Table 4.

Table 4

Constant parameter in Cura software

\begin{tabular}{|llllll|}
\hline $\begin{array}{l}\text { thickness of the } \\
\text { initial layer }(\mathrm{mm})\end{array}$ & $\begin{array}{l}\text { Width of each } \\
\text { layer }(\mathrm{mm})\end{array}$ & $\begin{array}{l}\text { Number } \\
\text { of walls }\end{array}$ & $\begin{array}{l}\text { Walled } \\
\text { thickness } \\
(\mathrm{mm})\end{array}$ & $\begin{array}{l}\text { Internal } \\
\text { infilling } \\
\text { pattern }\end{array}$ & $\begin{array}{l}\text { Printing } \\
\text { angle } \\
\text { (degree) }\end{array}$ \\
\hline 0.2 & 0.4 & 2 & 0.4 & Linear & 45 \\
\hline
\end{tabular}

Also, according to the melting point of PLA filament the nozzle temperature for printing all parts, was set at $210^{\circ} \mathrm{C}$. The printing angle of $\pm 45^{\circ}$ also gives better mechanical properties to the printed samples [ 72 , 73]. Because the printing time of a layer with an angle of $45^{\circ}$ is less than other angles, and this causes the bottom layer not to cool completely and as a result, more adhesion is created between the layers. Finally, give the prepared G-code to the FDM printer to print the sample using PLA filament. An example of a printed PLA specimen is shown in Fig. 8.

\section{Results And Discussion}

\subsection{Results of molecular dynamics simulation for PLA}

The mechanical and physical properties of PLA are shown in Fig. 11 and Table 5 by following the steps that mentioned in Sect. 2.2 are derived the mechanical, and physical properties. To draw the density 
diagram, first, the ensemble of NVT to maximize the energy of system is done. Next the ensemble of NPT is done to plot the density, as shown in Fig. 11, the density converges to $1.23 \mathrm{~g} / \mathrm{cm}^{3}$. Table 5 shown the comparison of mechanical, and physical properties of PLA with MDs modeling and experimental analysis.

Table 5

Comparison of mechanical and physical properties of PLA using by MDs modeling with experimental analysis

\begin{tabular}{|llll|}
\hline $\begin{array}{l}\text { Mechanical and } \\
\text { physical properties }\end{array}$ & $\begin{array}{l}\text { Simulation by } \\
\text { MDs method }\end{array}$ & Experimental & $\begin{array}{l}\text { Percentage error between } \\
\text { simulation and experimental test }\end{array}$ \\
\hline Density $\left(\mathrm{g} / \mathrm{cm}^{3}\right)$ & 1.23 & $1.24[74]$ & 0.80 \\
\hline Young's modulus $(\mathrm{GPa})$ & 3.5 & $3.5[75]$ & 0 \\
\hline Shear modulus $(\mathrm{GPa})$ & 2.2 & $2.4[76]$ & 8.33 \\
\hline Poisson's ratio & 0.29 & $0.3[77]$ & 3.33 \\
\hline
\end{tabular}

\subsection{Diagram of Radial Distribution Function}

One of the important quantities to evaluate the equilibrium validation of the system in molecular dynamics is the radial distribution function (RDF). The RDF expresses the mass distribution of the system over atomic distances that is expressed by relation (1).

$g(r)=\frac{\rho(r)}{\rho}=\frac{\left(N\left(r \pm \frac{\Delta r}{2}\right)\right)}{\Omega\left(r \pm \frac{\Delta r}{2}\right)} \frac{1}{\rho}$

In this respect $\frac{\rho(r)}{\rho}$ the density of the number of atoms in the shell to the radius $(r)$ in volume of $\Omega\left(r \pm \frac{\Delta r}{2}\right)$ and $\rho$ is the density of the number of atoms in the total volume of the system. For solids, the RDF at distances as shown in Fig. 12 must converge to the value of 1 . It is a measure of the equilibrium of a solid atom's system.

To validate the simulation results, the elastic stiffness matrix and elastic constants of the PLA were determined using a constant strain method. The elastic stiffness matrix components were defined for PLA, under a strain of 60.003 and at a pressure of $1 \mathrm{~atm}$ that this matrix is shown as follows: 


$C_{i j}(G P a)=\left[\begin{array}{cccccc}14.2630 & 3.1328 & 3.0219 & -6.3810 & 1.1522 & 1.4881 \\ 3.1328 & 14.3803 & 3.1782 & -1.5284 & 4.5940 & 1.4811 \\ 3.0219 & 3.1782 & 13.8417 & -1.3815 & 1.1766 & 4.8764 \\ -6.3810 & -1.5284 & -1.3815 & -1.2310 & -0.6570 & -0.7100 \\ 1.1522 & 4.5940 & 1.1766 & -0.6570 & -3.2538 & 0.2416 \\ 1.4881 & 1.4811 & 4.8764 & -0.7100 & 0.2416 & -3.3628\end{array}\right]$

As can be observed, because of the isotropy of the material, the diagonal elements are nearly similar and the matrix is approximately symmetric.

\subsection{Mechanical testing evaluation}

To investigate the effect of infilling density, print speed, and layer thickness on the mechanical properties of PLA samples made by FDM printer, first-four groups of samples SP1, SP2, SP3 and, SP4 were compared, then SP2 and SP5 samples and SP3 and SP6 samples were compared with each other. Usually, due to the long printing time and high consumption of filament, the parts are not printed completely solid. Infilling density is a parameter that is displayed as a percentage and indicates how much of a solid model should be filled with material when printing. Therefore, this quantity directly depends on the weight and construction time of the sample. Fig. 13 shows the stress-strain diagram of SP1, SP2, SP3, and SP4 with different density percentages.

Fig. 14 shows that the mechanical properties of printed specimens such as stiffness, ultimate strength and fracture strain are strongly dependent on the infilling density and they are directly proportional to the modulus of elasticity and strength. Fig. 14 also shows the broken specimens SP1 to SP4 after the tensile test. As can be seen, most of the specimens are broken in the failure range.

Also, by comparing the printing time of SP1 to SP4 parts in Table 3, it is proved that the filling density is directly related to the printing time. Table 6 shows the detail and average mechanical properties of SP1 SP6 specimens.

Table 6 Detail and average mechanical properties of SP1 - SP6 specimens 


\begin{tabular}{|c|c|c|c|c|c|}
\hline $\begin{array}{c}\text { Name of } \\
\text { specimens }\end{array}$ & $\begin{array}{l}\text { Percentage of } \\
\text { infilling density } \\
\text { (\%) }\end{array}$ & $\begin{array}{l}\text { E (GPa) } \\
\text { (For three } \\
\text { printed } \\
\text { samples) }\end{array}$ & $\begin{array}{l}\text { Elongation- } \\
\text { to-break (\%) } \\
\text { (For three } \\
\text { printed } \\
\text { samples) }\end{array}$ & $\begin{array}{l}\text { Strength } \\
\text { (MPa) } \\
\text { (For three } \\
\text { printed } \\
\text { samples) }\end{array}$ & $\begin{array}{l}\text { Weight }(\mathrm{g}) \\
\text { (For three } \\
\text { printed } \\
\text { samples) }\end{array}$ \\
\hline \multirow[t]{3}{*}{ SP1 } & \multirow[t]{3}{*}{20} & 1.156 & 1.487 & 13.380 & 5.028 \\
\hline & & 1.198 & 1.868 & 13.960 & 5.049 \\
\hline & & 1.201 & 2.104 & 14.350 & 5.080 \\
\hline \multirow[t]{3}{*}{ SP2 } & \multirow[t]{3}{*}{40} & 1.480 & 3.158 & 20.422 & 6.876 \\
\hline & & 1.362 & 3.449 & 19.810 & 6.951 \\
\hline & & 1.510 & 3.960 & 19.701 & 7.032 \\
\hline \multirow[t]{3}{*}{ SP3 } & \multirow[t]{3}{*}{60} & 1.695 & 3.565 & 23.480 & 8.329 \\
\hline & & 1.732 & 4.701 & 24.554 & 8.399 \\
\hline & & 1.780 & 5.010 & 25.062 & 8.451 \\
\hline \multirow[t]{3}{*}{ SP4 } & \multirow[t]{3}{*}{80} & 2.860 & 3.248 & 46.150 & 10.05 \\
\hline & & 3.467 & 2.551 & 43.460 & 10.15 \\
\hline & & 3.689 & 2.448 & 41.984 & 10.05 \\
\hline \multirow[t]{3}{*}{ SP5 } & \multirow[t]{3}{*}{80} & 1.540 & 3.740 & 22.29 & 7.09 \\
\hline & & 1.527 & 3.465 & 21.95 & 6.90 \\
\hline & & 1.567 & 3.650 & 22.20 & 6.95 \\
\hline \multirow[t]{3}{*}{ SP6 } & \multirow[t]{3}{*}{80} & 2.125 & 2.450 & 23.701 & 8.61 \\
\hline & & 2.007 & 2.458 & 23.665 & 8.89 \\
\hline & & 2.098 & 1.440 & 24.325 & 8.95 \\
\hline
\end{tabular}

Average mechanical properties of SP1 and SP6 specimens for easier access

$\begin{array}{cccccc}\begin{array}{c}\text { Name of } \\ \text { specimens }\end{array} & \begin{array}{c}\text { Percentage of } \\ \text { infilling density }\end{array} & \text { E (GPa) } & \begin{array}{c}\text { Elongation- } \\ \text { to-break (\%) }\end{array} & \begin{array}{c}\text { Strength } \\ (\mathrm{MPa})\end{array} & \text { Weight (g) }\end{array}$

(\%)

\begin{tabular}{cccccc}
\hline SP1 & 20 & $1.197 \pm 0.04$ & $1.892 \pm 0.41$ & $13.877 \pm 0.51$ & $5.16 \pm 0.036$ \\
\hline SP2 & 40 & $1.434 \pm 0.08$ & $3.546 \pm 0.41$ & $20.085 \pm 0.48$ & $6.76 \pm 0.288$ \\
\hline SP3 & 60 & $1.741 \pm 0.05$ & $4.184 \pm 0.83$ & $24.277 \pm 0.80$ & $8.39 \pm 0.061$ \\
\hline SP4 & 80 & $3.274 \pm 0.42$ & $2.848 \pm 0.40$ & $44.067 \pm 2.09$ & $10.09 \pm 0.06$ \\
\hline SP5 & 80 & $1.547 \pm 0.02$ & $3.604 \pm 0.14$ & $22.04 \pm 0.25$ & $6.98 \pm 0.12$ \\
\hline SP6 & 80 & $2.066 \pm 0.06$ & $1.948 \pm 0.51$ & $23.995 \pm 0.33$ & $8.78 \pm 0.18$ \\
\hline
\end{tabular}

Fig. 14 also shows the broken specimens SP1 to SP4 after the tensile test. As can be seen, most of the specimens are broken in the failure range. By comparing the values in Table 6 and the stress-strain diagrams in Fig. 13, it can be seen that as the internal network infilling density increases, its stiffness and strength increase dramatically. But from $60 \%$ density upwards the strain of failure is reduced. This means that as the filling density increases too much, the specimen becomes brittle and deforms less under a quasi-static load. If the failure strain of the SP4 part is ignored, this part can be considered as the best sample. As previously mentioned, the printing process in FDMs is based on melting the filament in the extruder and cooling the material at ambient temperature, and this is done layer by layer. These rapid 
heating and cooling, despite creating residual stress and internal defects in the part, cause it to become extremely brittle and increase its modulus of elasticity and strength and brittleness. Excluding SP4 specimens due to low fracture strain, by considering the modulus of elasticity the ultimate strength and fracture strain of SP3 with $60 \%$ density have higher mechanical properties among parts with filling density of 40,20 and $60 \%$. Also, between these three parts, SP2 sample (40\% part) has a higher strength and weight than the other two parts with a small difference. Therefore, it can be concluded that in cases where the strength of the part is less important than its form and appearance, a density of $40 \%$ is more appropriate in terms of cost, material and time savings.

\subsection{Investigating the effect of print speed}

The print speed is the same as the nozzle speed during printing. High printing speeds cause discontinuity of production in printing. The reason for this is the lack of time to melt and extrude the filament, which is very much related to the type of printer used and the mechanical specifications of the device, and precisely for this reason, any high speed cannot be printed with any printer. As mentioned in previous studies, low speeds were not considered at all. Therefore, in this study, two low print speeds were selected and the samples were printed with the same fabrication parameters. Fig. 15 shows the stress-strain diagram of the tensile test for two selected samples from the SP2 and SP5 groups.

Table 7 compares the numerical values of the mechanical properties of SP2 and SP5. As can be seen from the SP5 group diagram in Fig. 15, the reduction in print speed at low speeds has also led to an increase in mechanical properties such as stiffness, elongation-to-break, and ultimate strength. According to the printing time of each group of parts in Table 3, it can be seen that due to doubling the manufacturing time, the increase in properties has not been significant, but in cases where increasing the mechanical properties is important for the user, the specimen can be printed as quickly as possible to achieved the best properties. Fig. 16 also shows the broken specimens of SP2 and SP5 after the tensile test.

Table 7 Average mechanical properties of SP2 and SP5 specimens

\begin{tabular}{cccccc}
\hline $\begin{array}{c}\text { Samples } \\
\text { name }\end{array}$ & $\begin{array}{c}\text { Print } \\
\text { speed }(\mathrm{mm} / \mathrm{s})\end{array}$ & E (GPa) & $\begin{array}{c}\text { Elongation-to- } \\
\text { break }(\%)\end{array}$ & $\begin{array}{c}\text { Strength } \\
(\mathrm{MPa})\end{array}$ & Weight (g) \\
\hline SP2 & 40 & $1.434 \pm 0.08$ & $3.546 \pm 0.41$ & $20.085 \pm 0.48$ & $6.70 \pm 0.28$ \\
\hline SP5 & 20 & $1.547 \pm 0.02$ & $3.604 \pm 0.14$ & $22.04 \pm 0.25$ & $6.98 \pm 0.12$ \\
\hline
\end{tabular}

\subsection{Investigating the effect of layer thickness}

Since 3D printing technologies make the specimens layer by layer, the thickness of each of these layers in the print determines the quality of the specimens. In this study, two groups of SP3 and SP6 pieces with a difference in layer thickness of $0.1 \mathrm{~mm}$ were tested to investigate the effect of layer thickness on the mechanical properties of printed parts. Fig. 17 shows the obtained stress-strain diagram from the tensile test of one of the components of SP3 and SP5 groups. Numerical values of the mechanical properties are also summarized in Table 8. 
Table 8 Mechanical properties of SP3 and SP6 specimens

\begin{tabular}{cccccc}
\hline $\begin{array}{c}\text { Samples } \\
\text { name }\end{array}$ & $\begin{array}{c}\text { Thickness of layers } \\
(\mathrm{mm})\end{array}$ & $\mathrm{E}(\mathrm{GPa})$ & $\begin{array}{c}\text { Elongation-to- } \\
\text { break }(\%)\end{array}$ & $\begin{array}{c}\text { Strength } \\
(\mathrm{MPa})\end{array}$ & Weight (g) \\
\hline SP3 & 0.2 & $1.741 \pm 0.05$ & $4.184 \pm 0.83$ & $24.277 \pm 0.80$ & $8.39 \pm 0.06$ \\
\hline SP6 & 0.1 & $2.066 \pm 0.06$ & $1.948 \pm 0.51$ & $23.995 \pm 0.33$ & $8.78 \pm 0.18$ \\
\hline
\end{tabular}

The results show that reducing thickness of the layers leads to a slight increase in weight and stiffness of the part while greatly reducing the fracture strain. Therefore, the thickness of the layer has the greatest effect on the fracture strain of the piece and is inversely proportional to it. On the other hand, many researchers have shown that the thickness of the layers also has a significant effect on the dimensional accuracy and surface quality of the printed part, and as shown in Table 9, the dimensional accuracy of the SP6 sample group is closer to the standard dimensions of ASTM. Fig. 18 also shows images of broken specimens SP3 and SP6 after tensile testing.

Table 9 Dimensional accuracy of SP3 and SP6 specimens

\begin{tabular}{ccc}
\hline Sample name & The middle width of the sample $(\mathrm{mm})$ & Sample thickness $(\mathrm{mm})$ \\
\hline Standard of ASTM & 13 & 3.2 \\
\hline SP3 & $13.68 \pm 0.35$ & $3.39 \pm 0.46$ \\
\hline SP6 & $13.47 \pm 0.23$ & $3.27 \pm 0.03$ \\
\hline
\end{tabular}

Comparing the fabrication time of SP3 and SP6 parts according to Table 3, it can be seen that although the layer thickness decreases, the dimensional accuracy and surface quality increase, the printing time becomes longer because the thickness of each layer becomes thinner and the printer has to print more layers to make the whole part, which takes more time to complete the manufacturing process.

\section{Conclusion}

In this study, the effect of different parameters on the tensile properties of printed PLA samples by fused depositional modeling with MDs method and experimental analysis were investigated. For this purpose, in addition to the effect of three parameters of layer thickness, print speed, and internal network infilling density on the tensile properties of PLA polymer parts made by FDM printer, the most cost-effective parameters (in terms of cost and time) have also been extracted. The obtained experimental results from tensile experiments show that with increasing the infilling density, the mechanical properties of the parts increase significantly. However, at very high in filling densities, the components behave more brittle and have lower strain fractures, so in cases where the strength of the part is less important than its shape and appearance, a density of $40 \%$ is more appropriate in terms of cost, material and time savings. It was also observed that the printing speed has less effect on the mechanical properties of PLA parts than other parameters and it has increased the mechanical properties. It was also observed that reducing the thickness of the layer, while slightly increasing the stiffness of the parts, makes the part extremely brittle and on the other hand, it causes the increases the dimensional accuracy and surface quality of the specimens. Therefore, if the beauty and appearance accuracy of the part is a priority, the thickness of the 
lower layers is more suitable for this, otherwise the thickness of the higher layer causes faster and cheaper construction and also gives better mechanical properties to the specimen.

\section{Declarations}

\section{Acknowledgment}

The authors are thankful to the Iranian Nanotechnology Development Committee for their financial support and the University of Kashan for supporting this work by Grant No. 988093/14 and the micro and nanomechanics laboratory by Grant No. 992020/2.

\section{Consent to Publish}

The article is approved by all authors for publication.

\section{Authors Contributions}

Ashkan Farazin performed the experimental and MDs calculations. Dr. Mehdi Mohammadimehr proof the language of the manuscript. Authors contributing to the final version of the manuscript.

\section{Funding}

The authors have been received financial support for the research, authorship, and publication of this article at University of Kashan by Grant No. $988093 / 14$ and the micro and nanomechanics laboratory by Grant No. 992020/2.

\section{Competing Interest}

No conflict of interest exists in the submission of this article.

\section{Availability of data and materials}

Data required to reproduce these findings have been given in the text.

\section{Ethical Approval}

Not applicable

Consent to Participate

Not applicable

\section{References}


1. Velu R, Vaheed N, Ramachandran MK, Raspall F (2020) Correction to: Experimental investigation of robotic 3D printing of high-performance thermoplastics (PEEK): a critical perspective to support automated fibre placement process. Int J Adv Manuf Technol 108:1027-1027. https://doi.org/10.1007/s00170-019-04763-2

2. Chen T, Wang Y-C (2019) An advanced loT system for assisting ubiquitous manufacturing with 3D printing. Int J Adv Manuf Technol 103:1721-1733. https://doi.org/10.1007/s00170-019-03691-5

3. Ayrilmis N, Kariz M, Kwon JH, Kitek Kuzman M (2019) Effect of printing layer thickness on water absorption and mechanical properties of 3D-printed wood/PLA composite materials. Int J Adv Manuf Technol 102:2195-2200. https://doi.org/10.1007/s00170-019-03299-9

4. Huang C-Y, Ho C-F, Kuo H-J et al (2019) Development of a mirascope using 3D printing. Int J Adv Manuf Technol 102:2275-2283. https://doi.org/10.1007/s00170-018-3145-9

5. Wang Y-C, Chen T, Yeh Y-L (2019) Advanced 3D printing technologies for the aircraft industry: a fuzzy systematic approach for assessing the critical factors. Int J Adv Manuf Technol 105:40594069. https://doi.org/10.1007/s00170-018-1927-8

6. Ayrilmis N (2018) Effect of layer thickness on surface properties of 3D printed materials produced from wood flour/PLA filament. Polym Test 71:163-166.

https://doi.org/10.1016/j.polymertesting.2018.09.009

7. Hedayati SK, Behravesh AH, Hasannia S et al (2020) 3D printed PCL scaffold reinforced with continuous biodegradable fiber yarn: A study on mechanical and cell viability properties. Polym Test 83:106347. https://doi.org/10.1016/j.polymertesting.2020.106347

8. Muñoz I, Alonso-Madrid J, Menéndez-Muñiz M et al (2021) Life cycle assessment of integrated additive-subtractive concrete 3D printing. Int J Adv Manuf Technol 112:2149-2159. https://doi.org/10.1007/s00170-020-06487-0

9. Chen S, Hassanzadeh-Aghdam MK, Ansari R (2018) An analytical model for elastic modulus calculation of SiC whisker-reinforced hybrid metal matrix nanocomposite containing SiC nanoparticles. J Alloys Compd 767:632-641. https://doi.org/10.1016/j.jallcom.2018.07.102

10. Mou B, Zhao F, Qiao Q et al (2019) Flexural behavior of beam to column joints with or without an overlying concrete slab. Eng Struct 199:109616. https://doi.org/10.1016/j.engstruct.2019.109616

11. Mou B, Li X, Bai Y, Wang L (2019) Shear Behavior of Panel Zones in Steel Beam-to-Column Connections with Unequal Depth of Outer Annular Stiffener. J Struct Eng 145:04018247. https://doi.org/10.1061/(ASCE)ST.1943-541X.0002256

12. Lin J, Wang $Y$, Wei $X$ et al (2020) Controllable antibacterial and bacterially anti-adhesive surface fabricated by a bio-inspired beetle-like macromolecule. Int J Biol Macromol 157:553-560. https://doi.org/10.1016/j.ijbiomac.2020.04.207

13. Lin J, Cai X, Liu Z et al (2020) Anti-liquid-Interfering and Bacterially Antiadhesive Strategy for Highly Stretchable and Ultrasensitive Strain Sensors Based on Cassie-Baxter Wetting State. Adv Funct Mater 30:2000398. https://doi.org/10.1002/adfm.202000398 
14. Yang Z, Xu P, Wei W et al (2020) Influence of the Crosswind on the Pantograph Arcing Dynamics. IEEE Trans Plasma Sci 48:2822-2830. https://doi.org/10.1109/TPS.2020.3010553

15. Liu C, Wang F, He L et al (2020) Experimental and numerical investigation on dynamic responses of the umbrella membrane structure excited by heavy rainfall. J Vib Control 107754632093269. https://doi.org/10.1177/1077546320932691

16. Liu C, Wang F, Deng X et al (2021) Hailstone-induced dynamic responses of pretensioned umbrella membrane structure. Adv Struct Eng 24:3-16. https://doi.org/10.1177/1369433220940149

17. Liu C, Deng X, Liu J et al (2020) Dynamic response of saddle membrane structure under hail impact. Eng Struct 214:110597. https://doi.org/10.1016/j.engstruct.2020.110597

18. Zuo C, Chen Q, Tian L et al (2015) Transport of intensity phase retrieval and computational imaging for partially coherent fields: The phase space perspective. Opt Lasers Eng 71:20-32. https://doi.org/10.1016/j.optlaseng.2015.03.006

19. Qian J, Feng S, Li Y et al (2020) Single-shot absolute 3D shape measurement with deep-learningbased color fringe projection profilometry. Opt Lett 45:1842. https://doi.org/10.1364/OL.388994

20. Qian J, Feng S, Tao T et al (2020) Deep-learning-enabled geometric constraints and phase unwrapping for single-shot absolute 3D shape measurement. APL Photonics 5:046105. https://doi.org/10.1063/5.0003217

21. Hu J, Lin J, Zhang Y et al (2019) A new anti-biofilm strategy of enabling arbitrary surfaces of materials and devices with robust bacterial anti-adhesion via a spraying modified microsphere method. J Mater Chem A 7:26039-26052. https://doi.org/10.1039/C9TA07236E

22. Lin J, Hu J, Wang W et al (2021) Thermo and light-responsive strategies of smart titanium-containing composite material surface for enhancing bacterially anti-adhesive property. Chem Eng J 407:125783. https://doi.org/10.1016/j.cej.2020.125783

23. Zuo C, Sun J, Li J et al (2017) High-resolution transport-of-intensity quantitative phase microscopy with annular illumination. Sci Rep 7:7654. https://doi.org/10.1038/s41598-017-06837-1

24. Khosravani MR, Zolfagharian A, Jennings M, Reinicke T (2020) Structural performance of 3D-printed composites under various loads and environmental conditions. Polym Test 91:106770. https://doi.org/10.1016/j.polymertesting.2020.106770

25. Aziz R, Ul Haq MI, Raina A (2020) Effect of surface texturing on friction behaviour of 3D printed polylactic acid (PLA). Polym Test 85:106434. https://doi.org/10.1016/j.polymertesting.2020.106434

26. Alam Z, Sun L, Zhang $C$ et al (2021) Experimental and numerical investigation on the complex behaviour of the localised seismic response in a multi-storey plan-asymmetric structure. Struct Infrastruct Eng 17:86-102. https://doi.org/10.1080/15732479.2020.1730914

27. Zhang C, Wang H (2020) Swing vibration control of suspended structures using the Active Rotary Inertia Driver system: Theoretical modeling and experimental verification. Struct Control Heal Monit 27:. https://doi.org/10.1002/stc.2543

28. Zhang C, Gholipour G, Mousavi AA (2020) State-of-the-Art Review on Responses of RC Structures Subjected to Lateral Impact Loads. Arch Comput Methods Eng. https://doi.org/10.1007/s11831-020- 
09467-5

29. Abedini M, Zhang C (2020) Performance Assessment of Concrete and Steel Material Models in LSDYNA for Enhanced Numerical Simulation, A State of the Art Review. Arch Comput Methods Eng. https://doi.org/10.1007/s11831-020-09483-5

30. Liu S, Yu W, Chan FTS, Niu B (2021) A variable weight-based hybrid approach for multi-attribute group decision making under interval-valued intuitionistic fuzzy sets. Int J Intell Syst 36:1015-1052. https://doi.org/10.1002/int.22329

31. Zhan J, Tamura T, Li X et al (2020) Metal-plastic hybrid 3D printing using catalyst-loaded filament and electroless plating. Addit Manuf 36:101556. https://doi.org/10.1016/j.addma.2020.101556

32. Xu J, Zhang X, Liu Y et al (2020) Selective coaxial ink 3D printing for single-pass fabrication of smart elastomeric foam with embedded stretchable sensor. Addit Manuf 36:101487. https://doi.org/10.1016/j.addma.2020.101487

33. Maurel A, Haukka M, MacDonald E et al (2021) Considering lithium-ion battery 3D-printing via thermoplastic material extrusion and polymer powder bed fusion. Addit Manuf 37:101651. https://doi.org/10.1016/j.addma.2020.101651

34. Choi S, Ryu J, Lee M et al (2020) Support-free hollowing with spheroids and efficient 3D printing utilizing circular printing motions based on Voronoi diagrams. Addit Manuf 35:101254. https://doi.org/10.1016/j.addma.2020.101254

35. Kim D, Lee J, Kim G (2020) Biomimetic gelatin/HA biocomposites with effective elastic properties and 3D-structural flexibility using a 3D-printing process. Addit Manuf 36:101616. https://doi.org/10.1016/j.addma.2020.101616

36. Tu R, Sprague E, Sodano HA (2020) Precipitation printing towards diverse materials, mechanical tailoring and functional devices. Addit Manuf 35:101358. https://doi.org/10.1016/j.addma.2020.101358

37. Singh G, Missiaen J-M, Bouvard D, Chaix J-M (2021) Copper extrusion 3D printing using metal injection moulding feedstock: Analysis of process parameters for green density and surface roughness optimization. Addit Manuf 38:101778. https://doi.org/10.1016/j.addma.2020.101778

38. Dong Q, Cui L (2021) Reliability analysis of a system with two-stage degradation using Wiener processes with piecewise linear drift. IMA J Manag Math 32:3-29.

https://doi.org/10.1093/imaman/dpaa009

39. Zuo C, Chen Q, Gu G et al (2013) High-speed three-dimensional shape measurement for dynamic scenes using bi-frequency tripolar pulse-width-modulation fringe projection. Opt Lasers Eng 51:953960. https://doi.org/10.1016/j.optlaseng.2013.02.012

40. Hu Y, Chen Q, Feng S, Zuo C (2020) Microscopic fringe projection profilometry: A review. Opt Lasers Eng 135:106192. https://doi.org/10.1016/j.optlaseng.2020.106192

41. Zhang J, Sun J, Chen Q, Zuo C (2020) Resolution Analysis in a Lens-Free On-Chip Digital Holographic Microscope. IEEE Trans Comput Imaging 6:697-710. https://doi.org/10.1109/TCI.2020.2964247 
42. Zhang J, Chen Q, Sun J et al (2020) On a universal solution to the transport-of-intensity equation. Opt Lett 45:3649. https://doi.org/10.1364/OL.391823

43. Casavola C, Cazzato A, Moramarco V, Pappalettera G (2017) Residual stress measurement in Fused Deposition Modelling parts. Polym Test 58:249-255. https://doi.org/10.1016/j.polymertesting.2017.01.003

44. Aliheidari N, Tripuraneni R, Ameli A, Nadimpalli S (2017) Fracture resistance measurement of fused deposition modeling 3D printed polymers. Polym Test 60:94-101. https://doi.org/10.1016/j.polymertesting.2017.03.016

45. Aloyaydi B, Sivasankaran S, Mustafa A (2020) Investigation of infill-patterns on mechanical response of 3D printed poly-lactic-acid. Polym Test 87:106557. https://doi.org/10.1016/j.polymertesting.2020.106557

46. Li C, Sun L, Xu Z et al (2020) Experimental Investigation and Error Analysis of High Precision FBG Displacement Sensor for Structural Health Monitoring. Int J Struct Stab Dyn 20:2040011. https://doi.org/10.1142/S0219455420400118

47. Zhang C, Gholipour G, Mousavi AA (2020) Blast loads induced responses of RC structural members: State-of-the-art review. Compos Part B Eng 195:108066. https://doi.org/10.1016/j.compositesb.2020.108066

48. Alam Z, Zhang C, Samali B (2020) Influence of seismic incident angle on response uncertainty and structural performance of tall asymmetric structure. Struct Des Tall Spec Build 29:. https://doi.org/10.1002/tal.1750

49. Zhang C, Abedini M, Mehrmashhadi J (2020) Development of pressure-impulse models and residual capacity assessment of RC columns using high fidelity Arbitrary Lagrangian-Eulerian simulation. Eng Struct 224:111219. https://doi.org/10.1016/j.engstruct.2020.111219

50. Zhu L, Kong L, Zhang C (2020) Numerical Study on Hysteretic Behaviour of Horizontal-Connection and Energy-Dissipation Structures Developed for Prefabricated Shear Walls. Appl Sci 10:1240. https://doi.org/10.3390/app10041240

51. Croccolo D, De Agostinis M, Olmi G (2013) Experimental characterization and analytical modelling of the mechanical behaviour of fused deposition processed parts made of ABS-M30. Comput Mater Sci 79:506-518. https://doi.org/10.1016/j.commatsci.2013.06.041

52. Tymrak BM, Kreiger M, Pearce JM (2014) Mechanical properties of components fabricated with open-source 3-D printers under realistic environmental conditions. Mater Des 58:242-246. https://doi.org/10.1016/j.matdes.2014.02.038

53. Chacón JM, Caminero MA, García-Plaza E, Núñez PJ (2017) Additive manufacturing of PLA structures using fused deposition modelling: Effect of process parameters on mechanical properties and their optimal selection. Mater Des 124:143-157. https://doi.org/10.1016/j.matdes.2017.03.065

54. Kozior T, Kundera C (2017) Evaluation of the Influence of Parameters of FDM Technology on the Selected Mechanical Properties of Models. Procedia Eng 192:463-468. https://doi.org/10.1016/j.proeng.2017.06.080 
55. Mahmood S, Qureshi AJ, Goh KL, Talamona D (2017) Tensile strength of partially filled FFF printed parts: experimental results. Rapid Prototyp J 23:122-128. https://doi.org/10.1108/RPJ-08-20150115

56. Alafaghani A, Qattawi A, Alrawi B, Guzman A (2017) Experimental Optimization of Fused Deposition Modelling Processing Parameters: A Design-for-Manufacturing Approach. Procedia Manuf 10:791803. https://doi.org/10.1016/j.promfg.2017.07.079

57. Tronvoll SA, Elverum CW, Welo T (2018) Dimensional accuracy of threads manufactured by fused deposition modeling. Procedia Manuf 26:763-773. https://doi.org/10.1016/j.promfg.2018.07.088

58. Popescu D, Zapciu A, Amza C et al (2018) FDM process parameters influence over the mechanical properties of polymer specimens: A review. Polym Test 69:157-166.

https://doi.org/10.1016/j.polymertesting.2018.05.020

59. Khandan A, Saber-Samandari S, Telloo M et al (2020) A Mitral Heart Valve Prototype Using Sustainable Polyurethane Polymer: Fabricated by 3D Bioprinter, Tested by Molecular Dynamics Simulation. AUT J Mech Eng

60. Martin O, Avérous L (2001) Poly(lactic acid): plasticization and properties of biodegradable multiphase systems. Polymer 42:6209-6219. https://doi.org/10.1016/S0032-3861(01)00086-6

61. Gupta AP, Kumar V (2007) New emerging trends in synthetic biodegradable polymers - Polylactide: A critique. Eur Polym J 43:4053-4074. https://doi.org/10.1016/j.eurpolymj.2007.06.045

62. Gere D, Czigany T (2020) Future trends of plastic bottle recycling: Compatibilization of PET and PLA. Polym Test 81:106160. https://doi.org/10.1016/j.polymertesting.2019.106160

63. Kabir E, Kaur R, Lee J et al (2020) Prospects of biopolymer technology as an alternative option for non-degradable plastics and sustainable management of plastic wastes. J Clean Prod 258:120536. https://doi.org/10.1016/j.jclepro.2020.120536

64. Oksman K, Skrifvars M, Selin J-F (2003) Natural fibres as reinforcement in polylactic acid (PLA) composites. Compos Sci Technol 63:1317-1324. https://doi.org/10.1016/S0266-3538(03)00103-9

65. Letcher T, Waytashek M (2014) Material Property Testing of 3D-Printed Specimen in PLA on an EntryLevel 3D Printer. In: Volume 2A: Advanced Manufacturing. American Society of Mechanical Engineers

66. Rezgui F, Swistek M, Hiver JM et al (2005) Deformation and damage upon stretching of degradable polymers (PLA and PCL). Polymer 46:7370-7385. https://doi.org/10.1016/j.polymer.2005.03.116

67. Maroufkhani M, Katbab A, Liu W, Zhang J (2017) Polylactide (PLA) and acrylonitrile butadiene rubber (NBR) blends: The effect of ACN content on morphology, compatibility and mechanical properties. Polymer 115:37-44. https://doi.org/10.1016/j.polymer.2017.03.025

68. Farazin A, Aghdam HA, Motififard M et al (2019) A polycaprolactone bio-nanocomposite bone substitute fabricated for femoral fracture approaches: Molecular dynamic and micro-mechanical Investigation. J Nanoanalysis

69. Farazin A, Aghadavoudi F, Motififard M et al (2020) Nanostructure, molecular dynamics simulation and mechanical performance of PCL membranes reinforced with antibacterial nanoparticles. J Appl 


\section{Comput Mech}

70. Farazin A, Mohammadimehr M (2020) Nano research for investigating the effect of SWCNTs dimensions on the properties of the simulated nanocomposites: a molecular dynamics simulation. Adv nano Res 9:83-90

71. Tanikella NG, Wittbrodt B, Pearce JM (2017) Tensile strength of commercial polymer materials for fused filament fabrication 3D printing. Addit Manuf 15:40-47.

https://doi.org/10.1016/j.addma.2017.03.005

72. Lee C-Y, Liu C-Y (2019) The influence of forced-air cooling on a 3D printed PLA part manufactured by fused filament fabrication. Addit Manuf 25:196-203. https://doi.org/10.1016/j.addma.2018.11.012

73. Kakanuru P, Pochiraju K (2020) Moisture Ingress and Degradation of Additively Manufactured PLA, ABS and PLA/SiC Composite Parts. Addit Manuf 36:101529.

https://doi.org/10.1016/j.addma.2020.101529

74. Torre R, Brischetto S, Dipietro IR (2021) Buckling developed in 3D printed PLA cuboidal samples under compression: Analytical, numerical and experimental investigations. Addit Manuf 38:101790. https://doi.org/10.1016/j.addma.2020.101790

75. Ferrández-Montero A, Lieblich M, Benavente R et al (2020) Study of the matrix-filler interface in PLA/Mg composites manufactured by Material Extrusion using a colloidal feedstock. Addit Manuf 33:101142. https://doi.org/10.1016/j.addma.2020.101142

76. Romeijn T, Wells B, Wei D, Paul G (2020) Investigation into the shear property of thin-walled additively manufactured structures using staggered fused filament fabrication. Addit Manuf 35:101259. https://doi.org/10.1016/j.addma.2020.101259

77. Arh M, Slavič J, Boltežar M (2020) Experimental identification of the dynamic piezoresistivity of fused-filament-fabricated structures. Addit Manuf 36:101493. https://doi.org/10.1016/j.addma.2020.101493

\section{Figures}

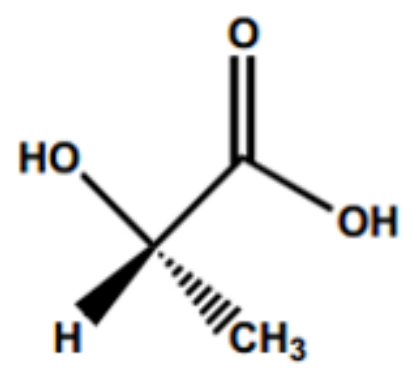

L-Lactic acid

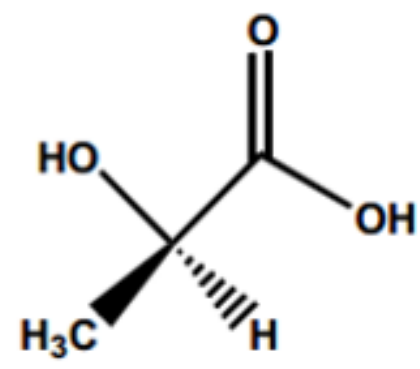

D-Lactic acid

\section{Figure 1}


Spatial isomers of lactic acid

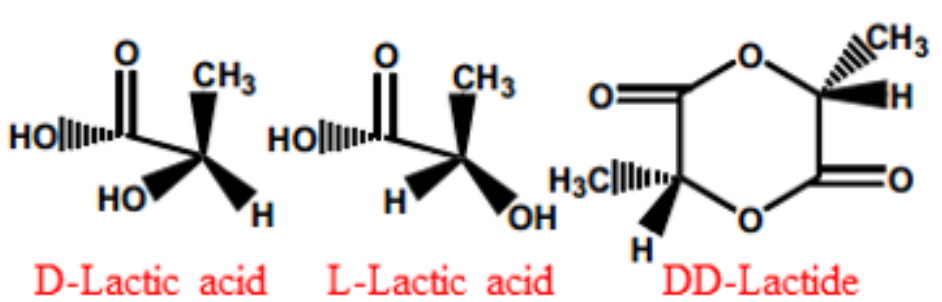

D-Lactic acid L-Lactic acid

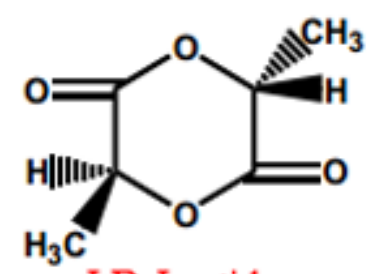

LD-Lactide

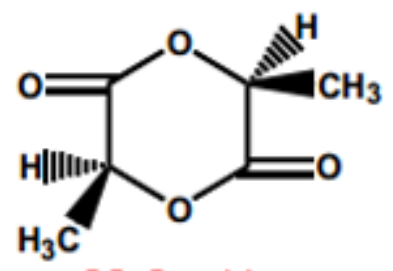

LL-Lactide

\section{Figure 2}

Spatial chemistry of lactic acid and lactide molecules
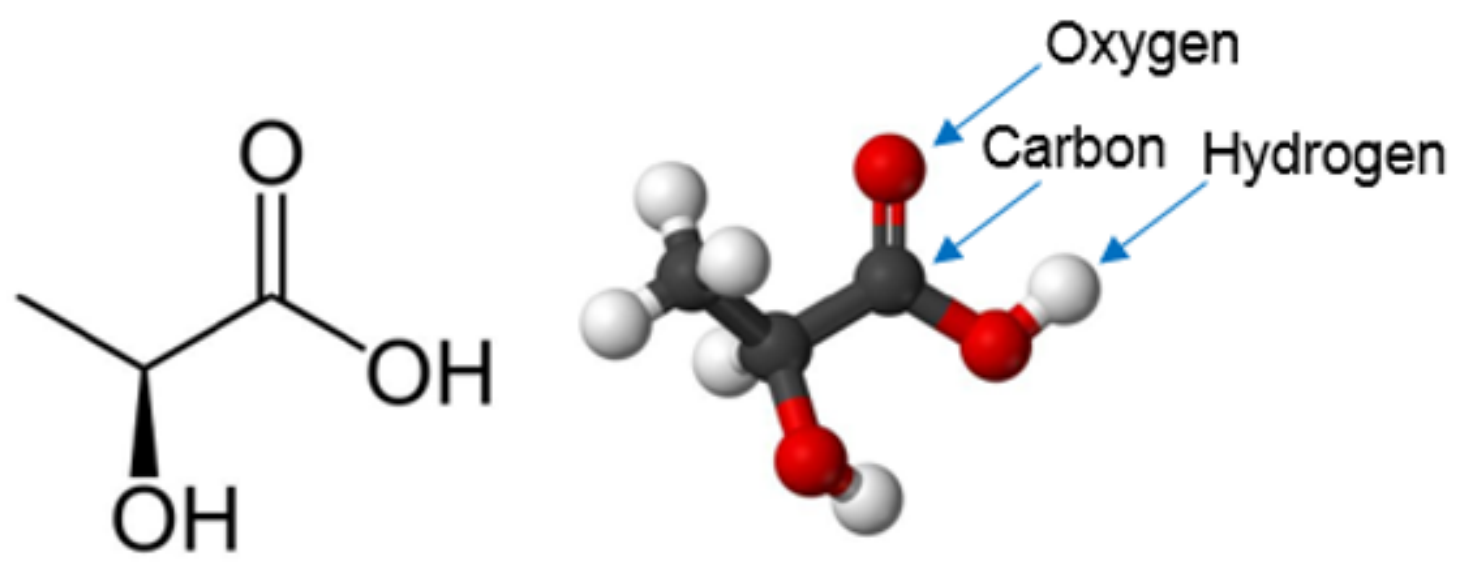

Figure 3

A monomer of simulated PLA that created by Materials studio software 


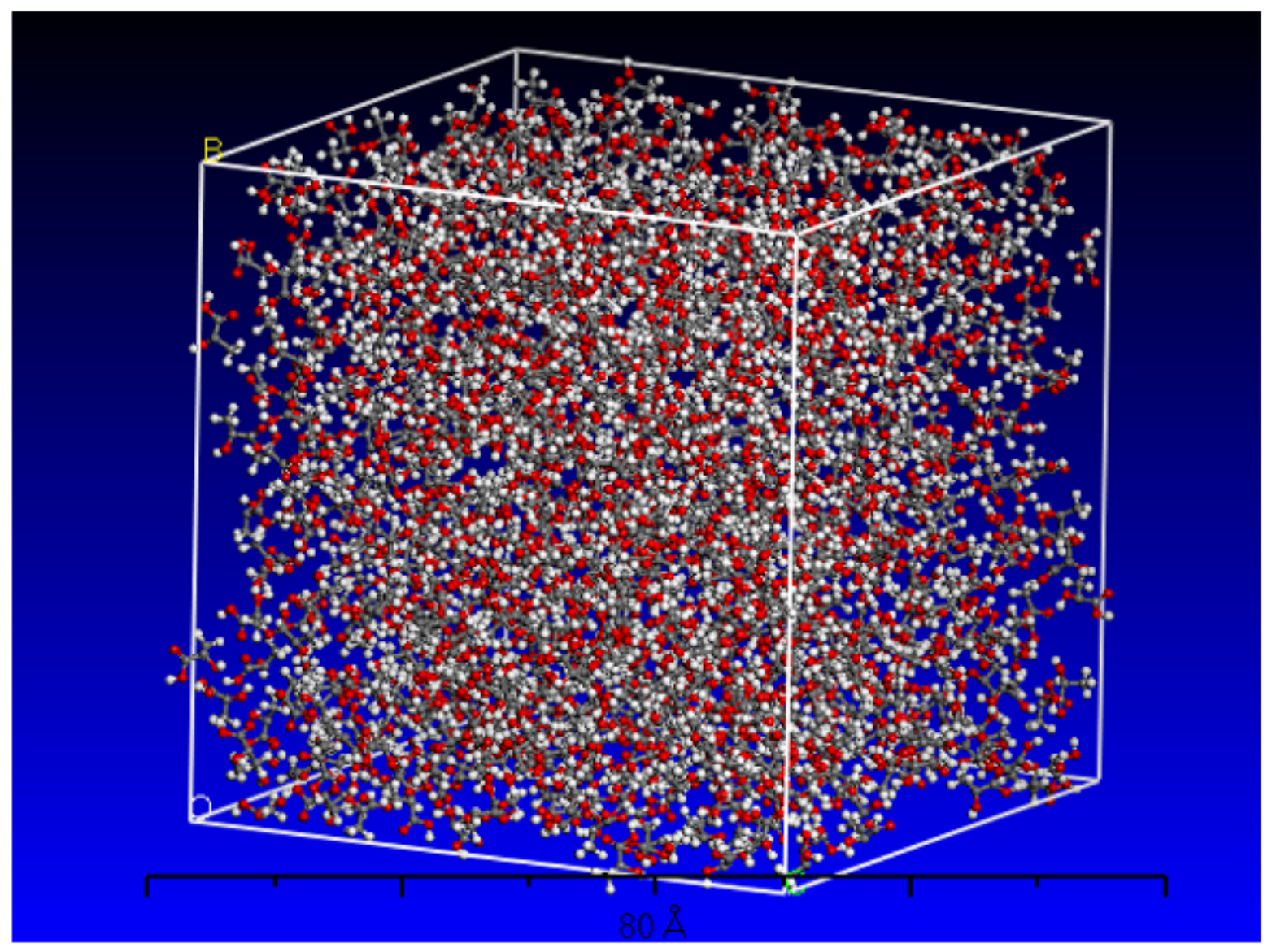

Figure 4

Simulation atomistic model of PLA in materials studio software

To obtain physical properties

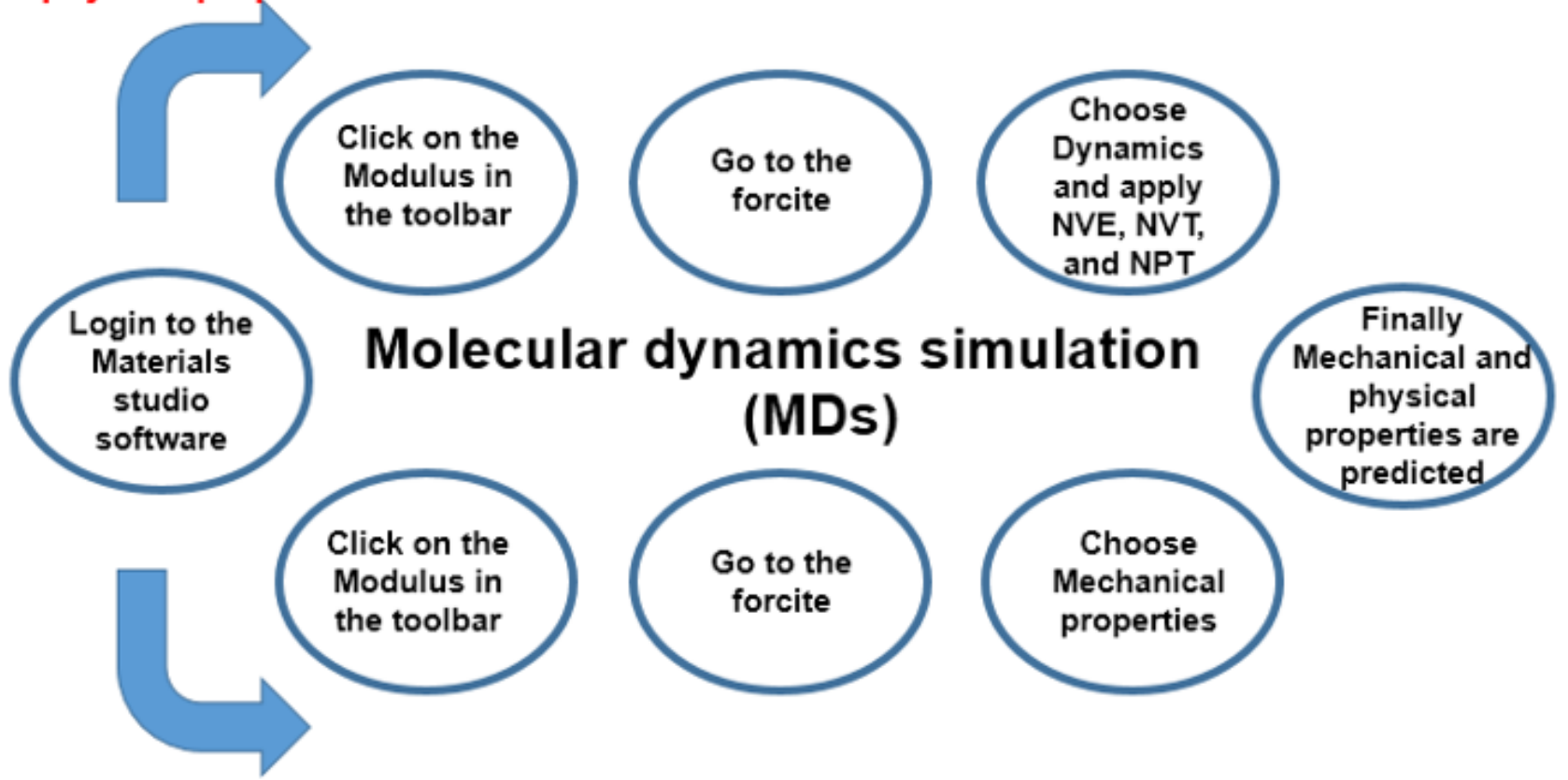

To obtain mechanical properties

Figure 5 
Steps to obtain the mechanical, and physical properties using Materials studio software

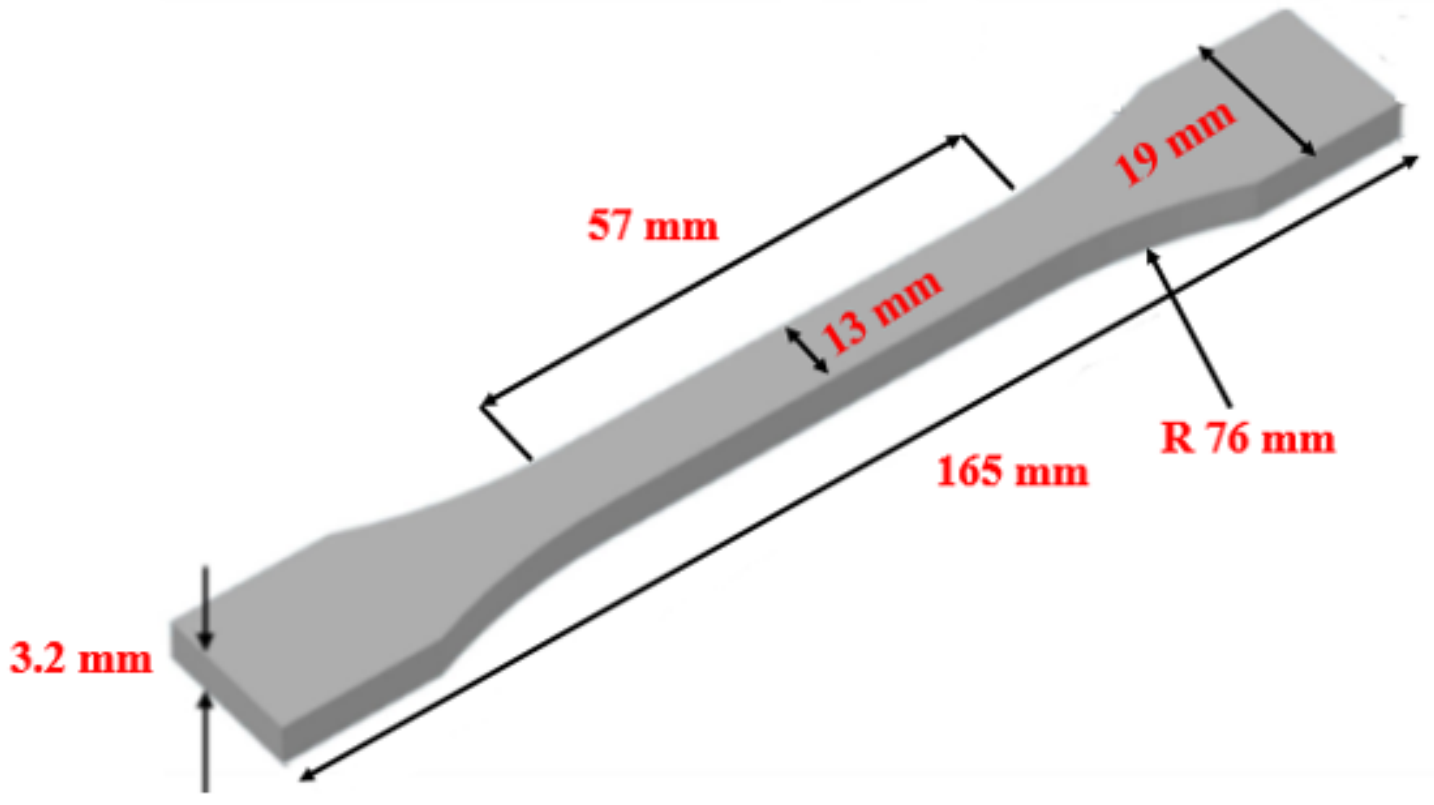

Figure 6

Dimensions of standard specimen (in millimeters) for plastics

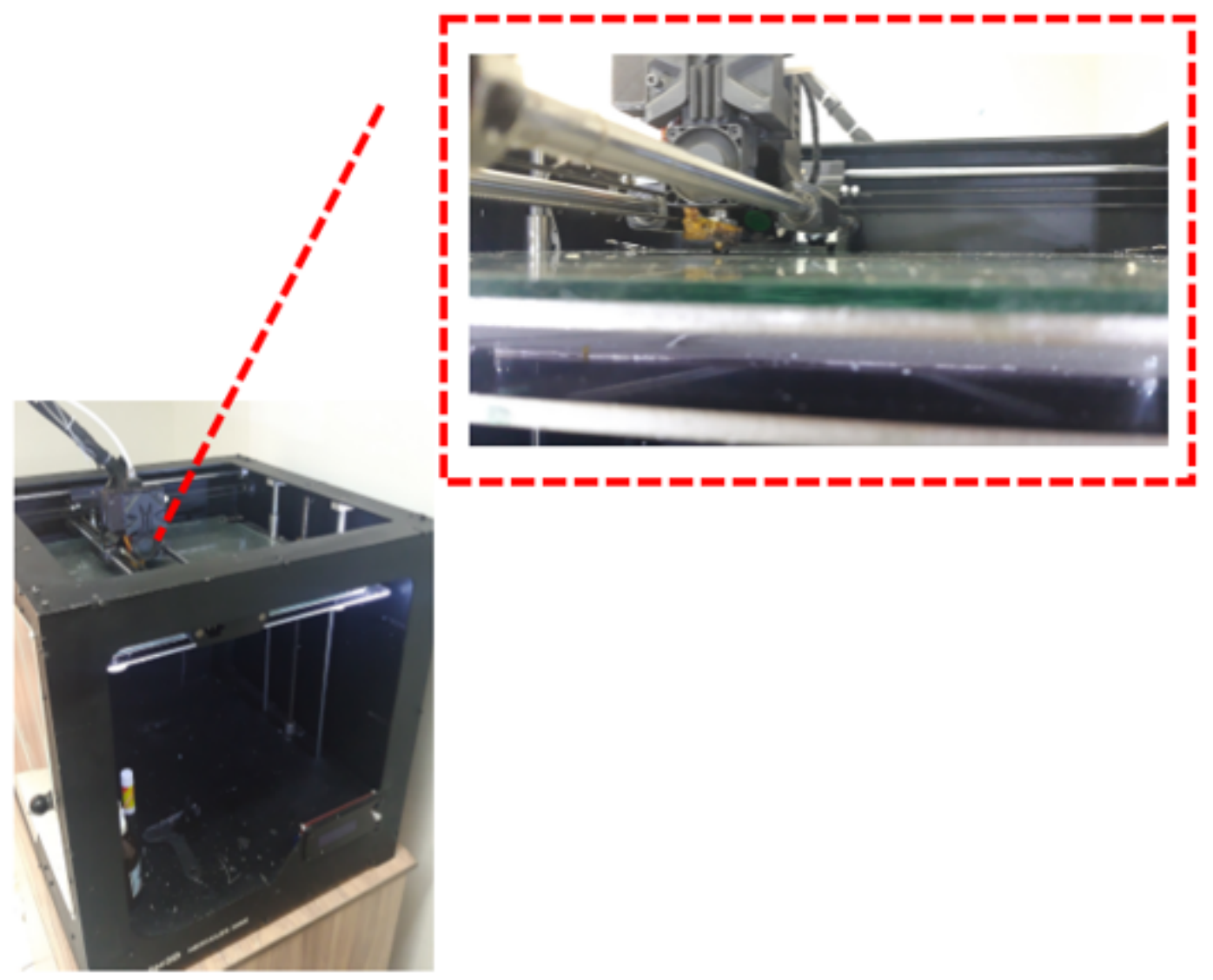

Figure 7

3D printer that printed specimens (SP1-SP6) in the present work 


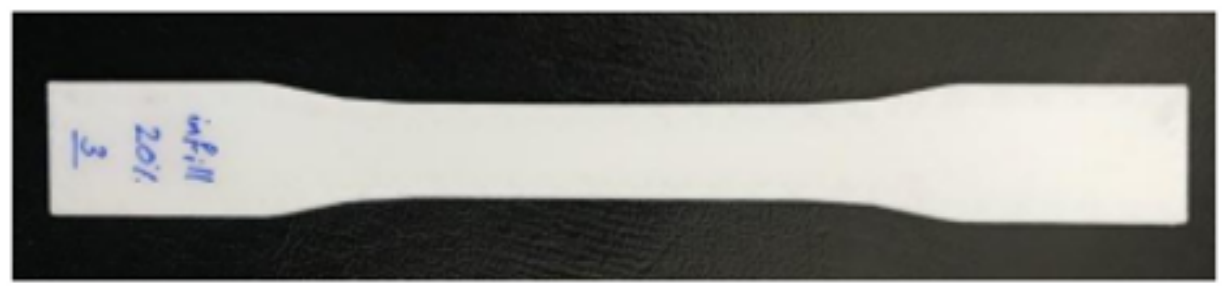

Figure 8

Overview of 3D printed specimen

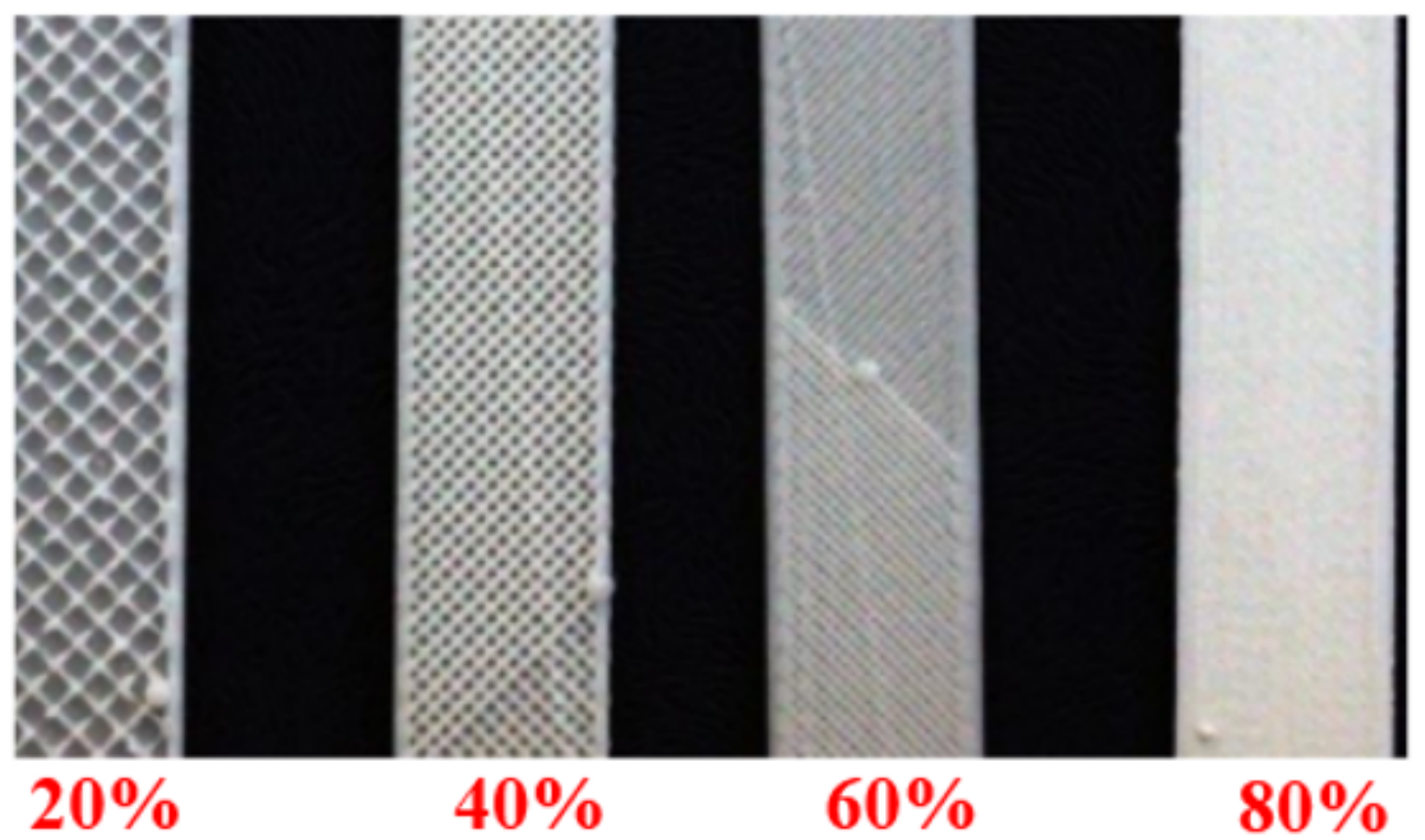

Figure 9

3D printed specimens with different infilling density 


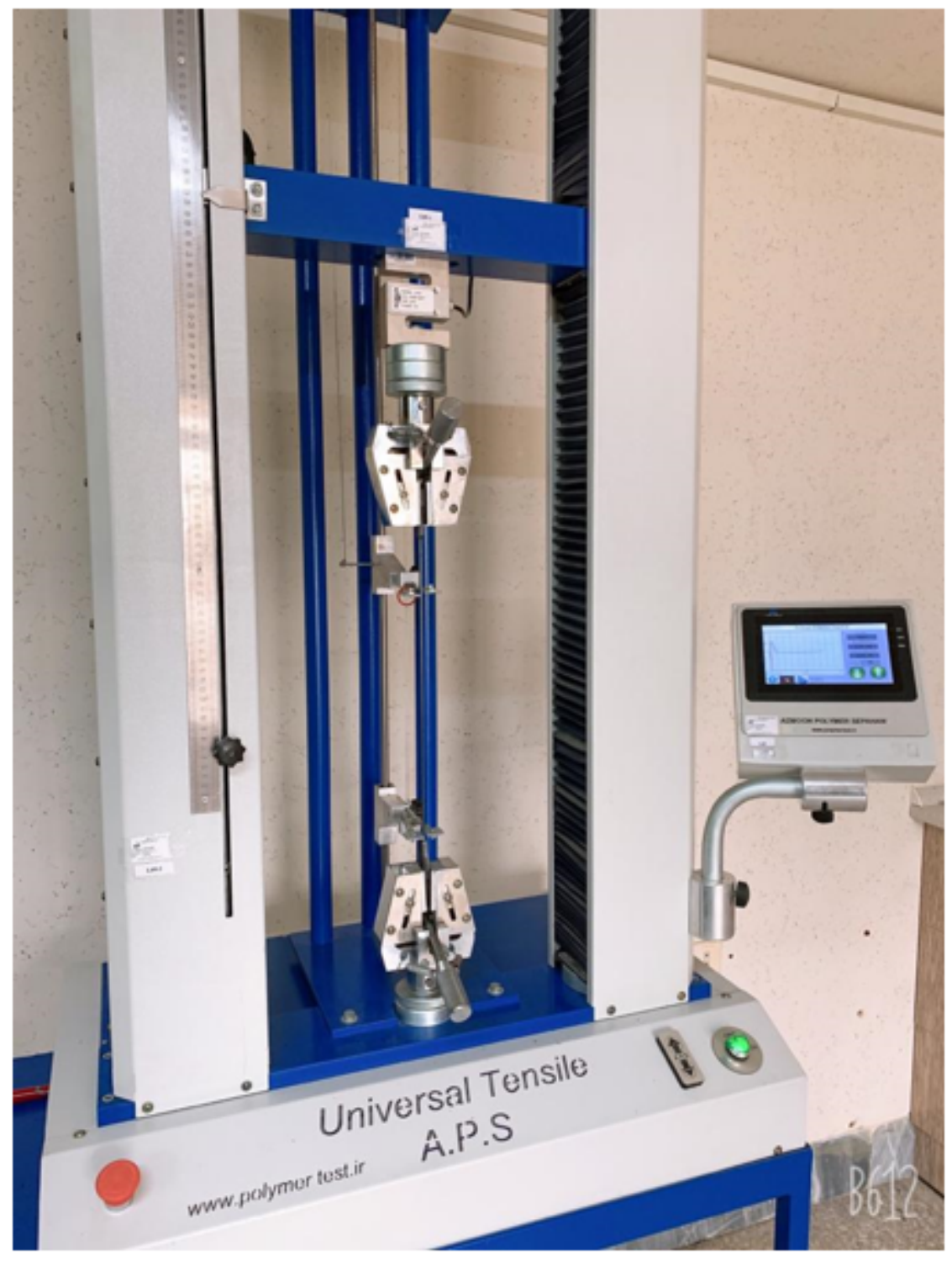

Figure 10

Schematic of tensile machine and specimens under quasi static tensile test 


\section{Forcite Dynamics Density}

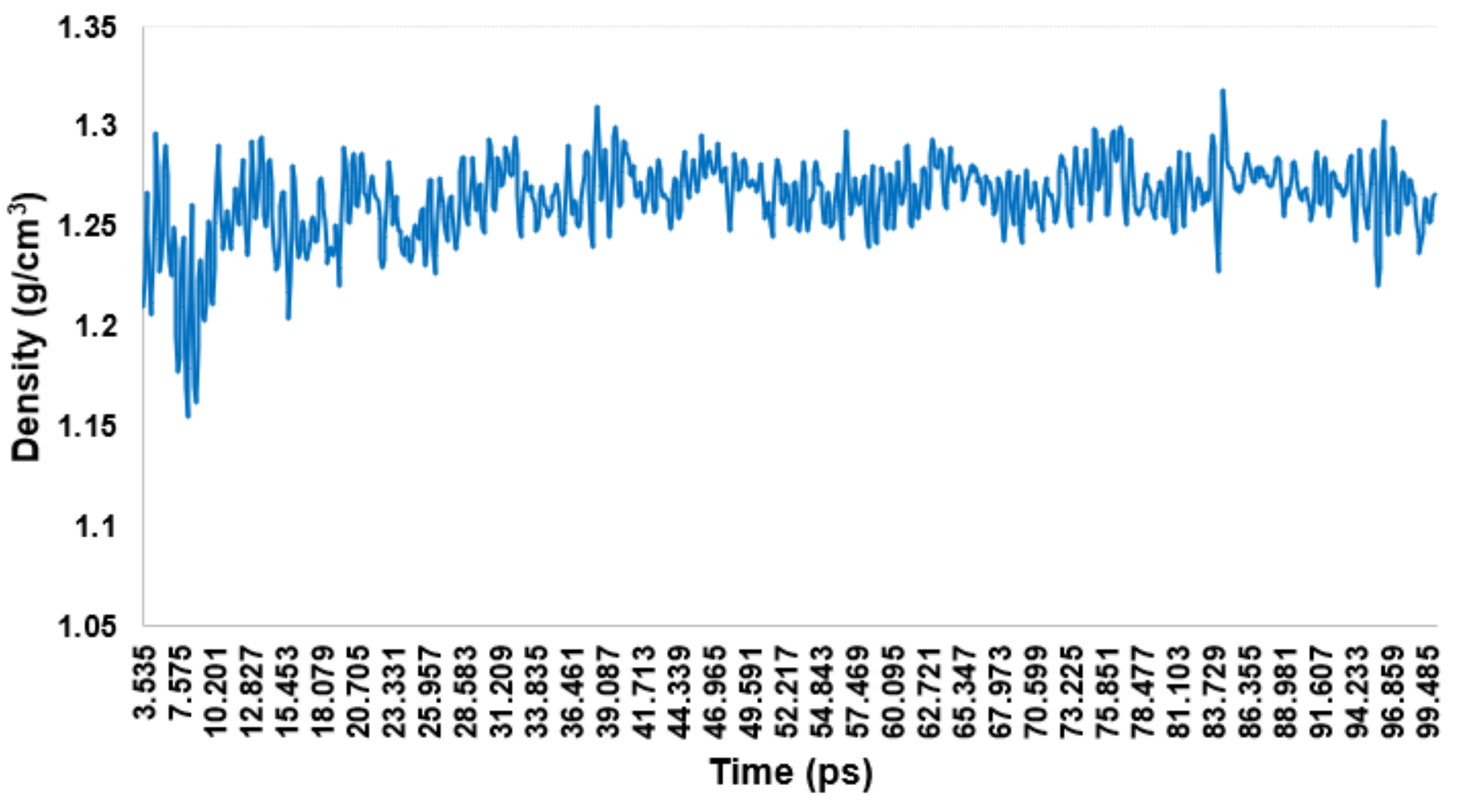

Figure 11

Density convergence during simulation for PLA at the temperature of $298{ }^{\circ} \mathrm{K}$ 


\section{Forcite Analysis-RDF}

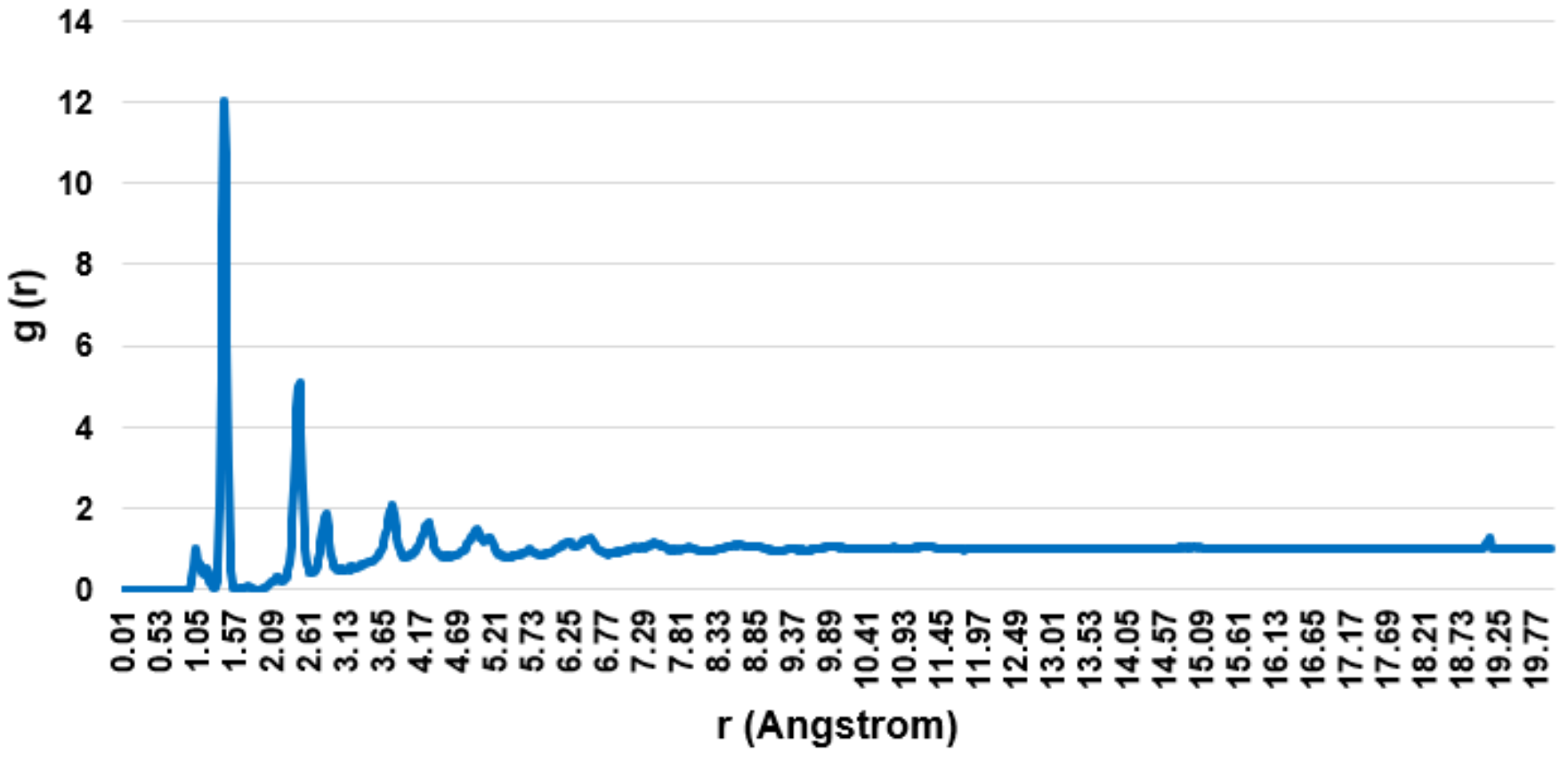

Figure 12

Diagram of the radial distribution of atoms that convergence to the number 1

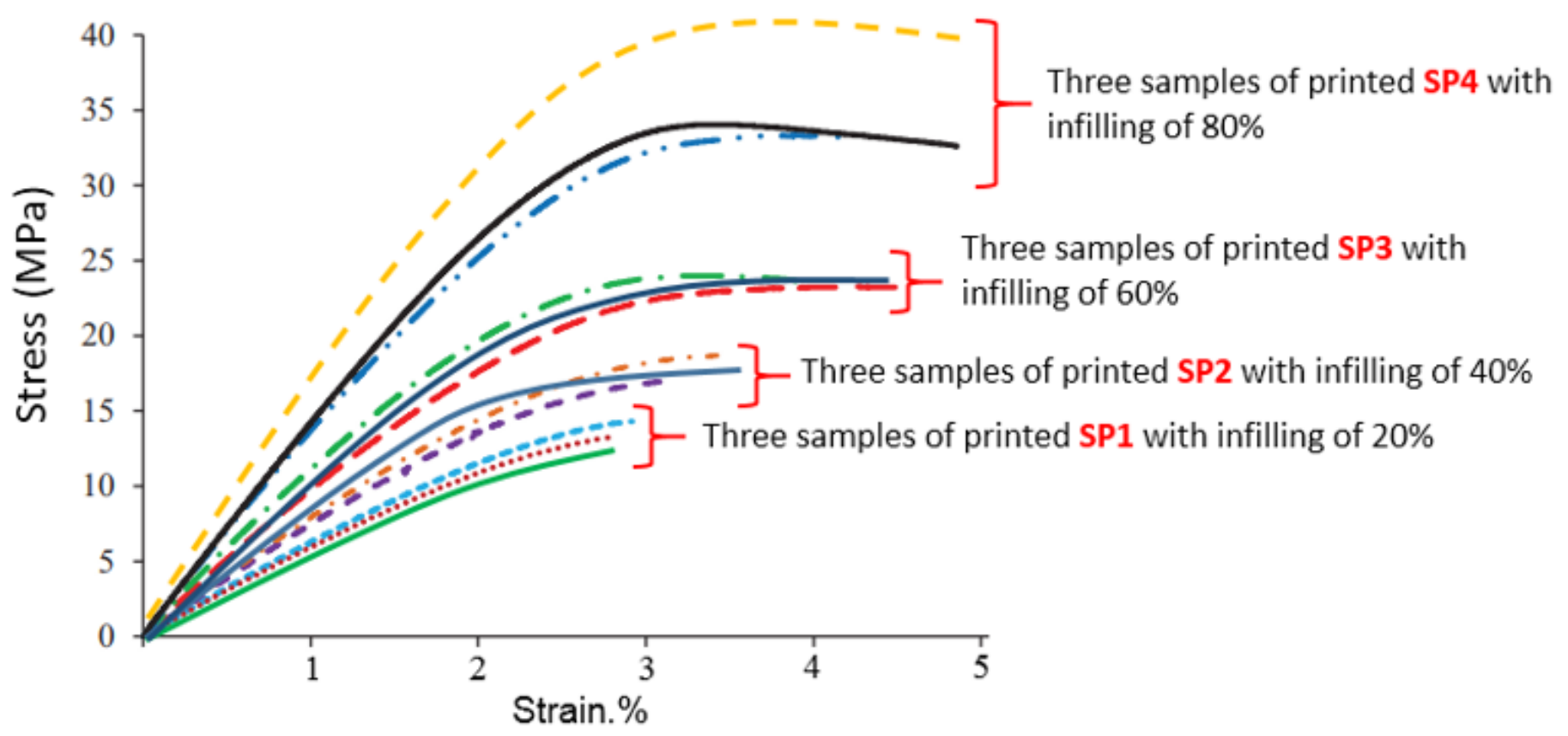

Figure 13 
The stress-strain curves of PLA specimens with different infilling density

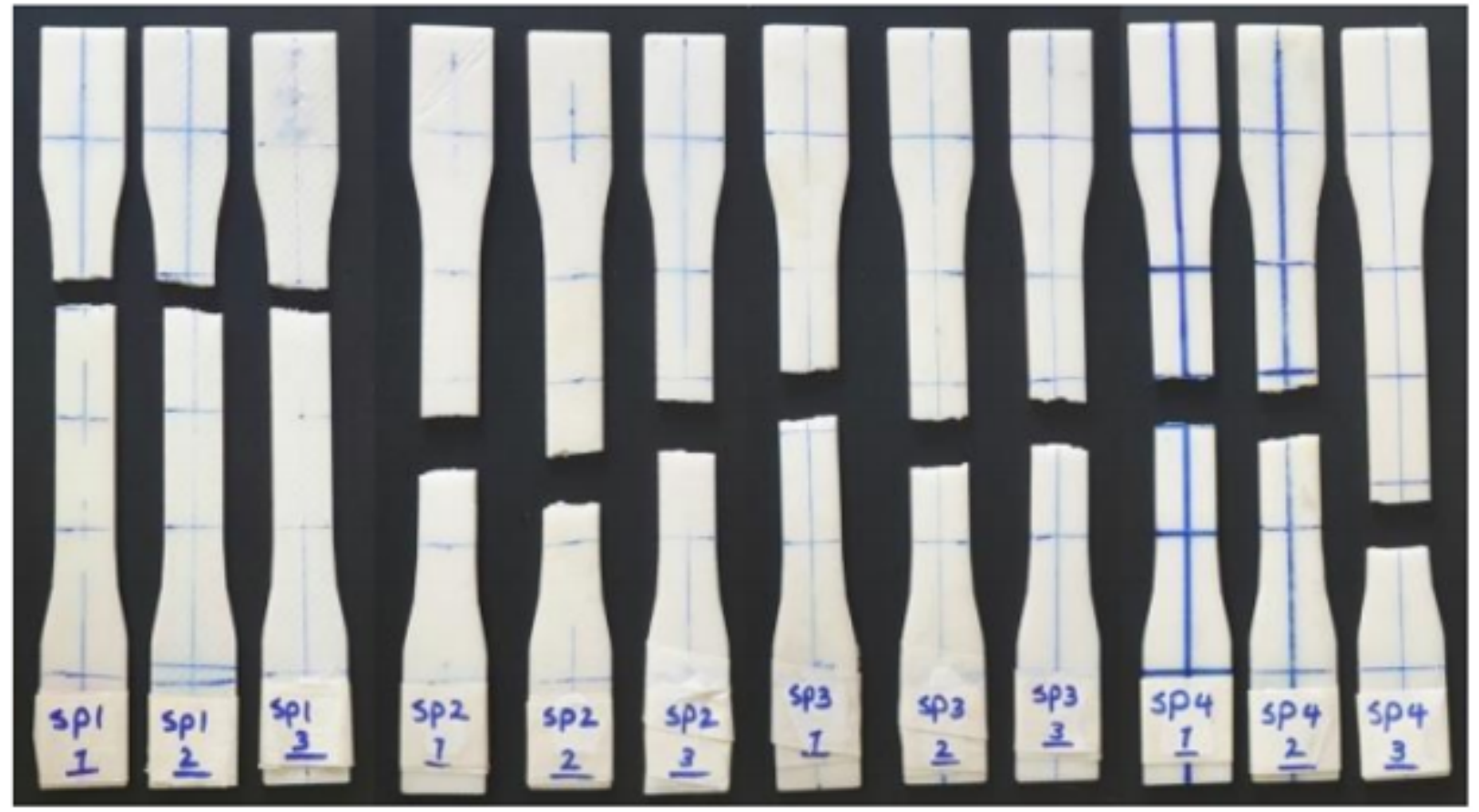

Figure 14

Samples of SP1 to SP4 after tensile test

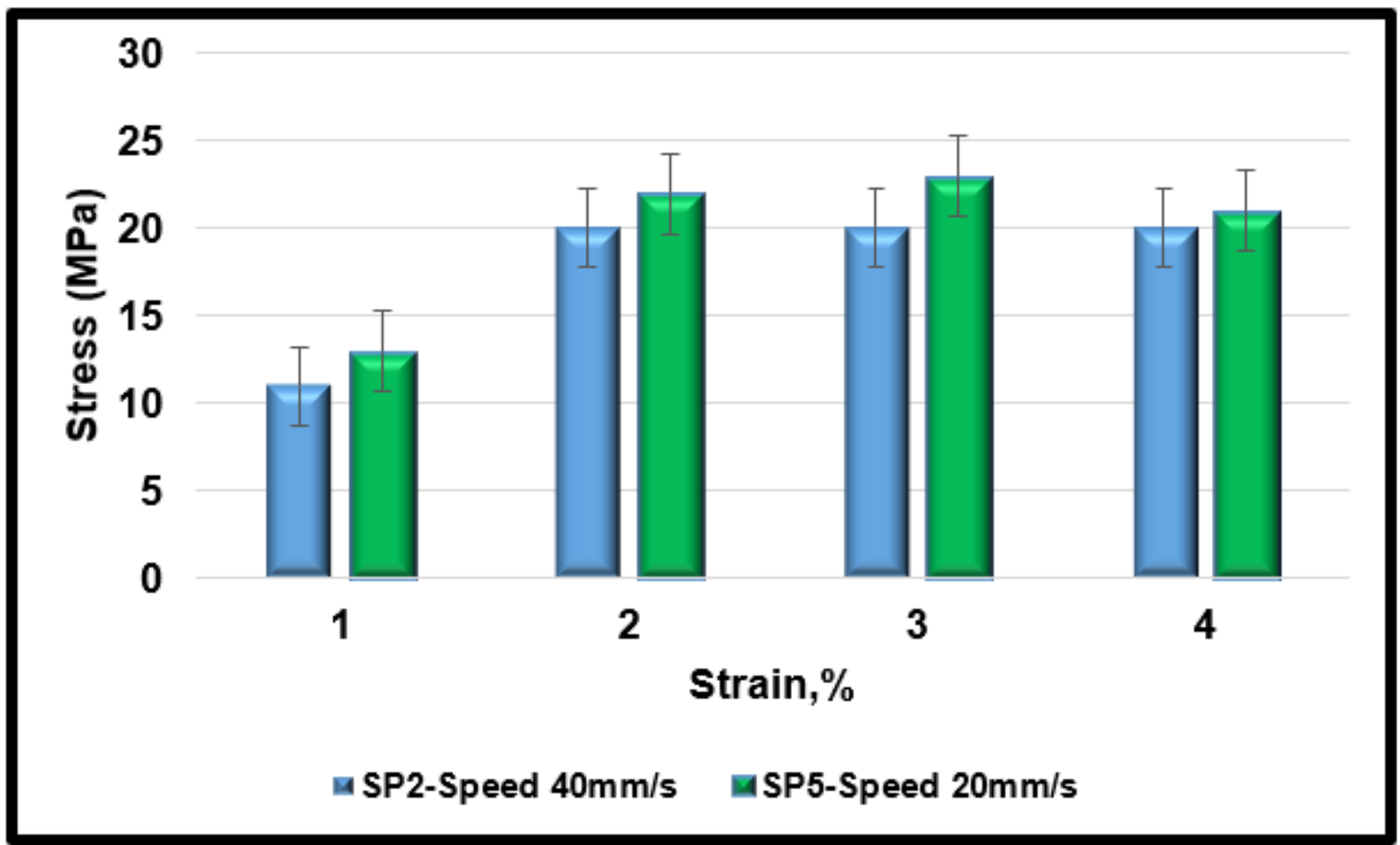

Figure 15

Stress-strain curves of PLA specimens with different printing speeds 


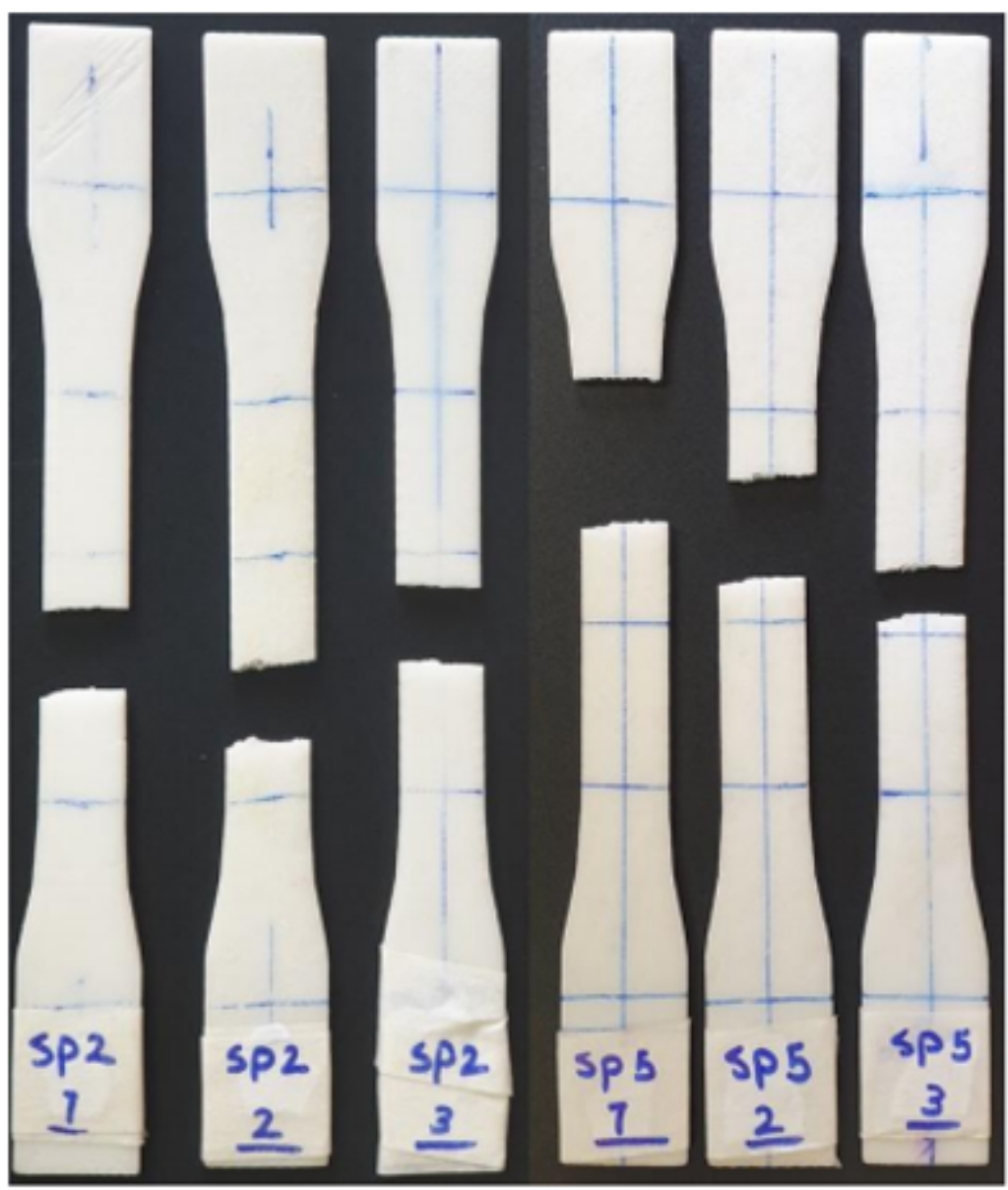

Figure 16

Samples of SP2 and SP5 after tensile test

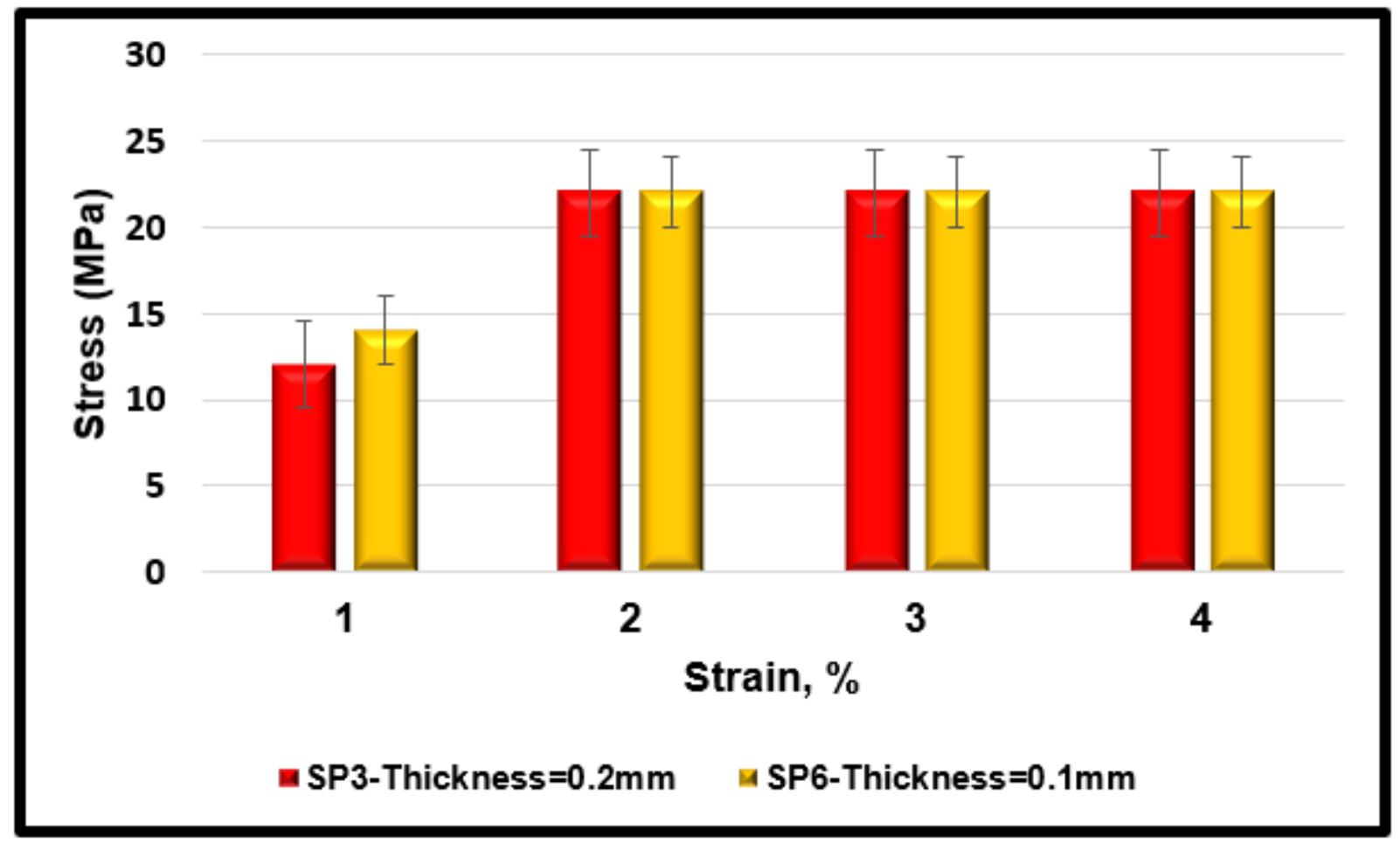


Figure 17

Stress-strain curves of PLA specimens with different layer thicknesses

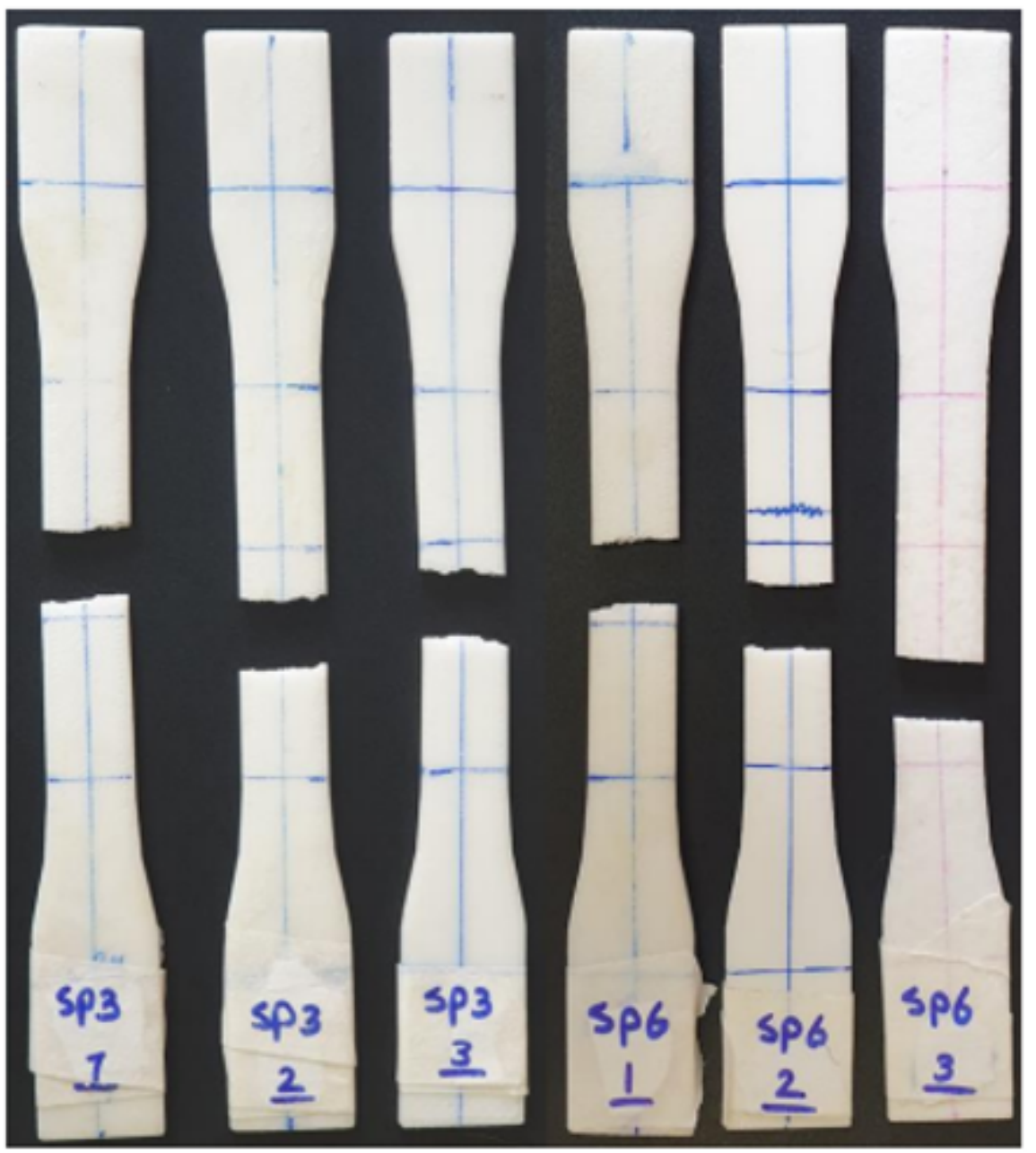

Figure 18

Samples of SP3 and SP6 after tensile test 